\title{
RICE ACYL-COA-BINDING PROTEIN6 Affects Acyl-CoA Homeostasis and Growth in Rice
}

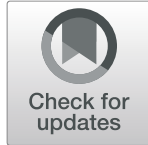

Wei Meng ${ }^{1,2^{*}}$ (D, Lijian X ${ }^{3}$, Zhi-Yan Du ${ }^{4}$, Fang Wang ${ }^{2}$, Rui Zhang ${ }^{5}$, Xingshun Song ${ }^{2}$, Sin Man Lam ${ }^{6,7}$, Guanghou Shui ${ }^{6}$ Y Yuhua $\mathrm{Li}^{1}$ and Mee-Len Chye ${ }^{5}$

\begin{abstract}
Backgrounds: Acyl-coenzyme A (CoA) esters are important intermediates in lipid metabolism with regulatory properties. Acyl-CoA-binding proteins bind and transport acyl-CoAs to fulfill these functions. RICE ACYL-COABINDING PROTEIN6 (OsACBP6) is currently the only one peroxisome-localized plant ACBP that has been proposed to be involved in $\beta$-oxidation in transgenic Arabidopsis. The role of the peroxisomal ACBP (OsACBP6) in rice (Oryza sativa) was investigated.
\end{abstract}

Results: Here, we report on the function of OsACBP6 in rice. The osacbp6 mutant showed diminished growth with reduction in root meristem activity and leaf growth. Acyl-CoA profiling and lipidomic analysis revealed an increase in acyl-CoA content and a slight triacylglycerol accumulation caused by the loss of OsACBP6. Comparative transcriptomic analysis discerned the biological processes arising from the loss of OsACBP6. Reduced response to oxidative stress was represented by a decline in gene expression of a group of peroxidases and peroxidase activities. An elevation in hydrogen peroxide was observed in both roots and shoots/leaves of osacbp6. Taken together, loss of OsACBP6 not only resulted in a disruption of the acyl-CoA homeostasis but also peroxidasedependent reactive oxygen species (ROS) homeostasis. In contrast, osacbp6-complemented transgenic rice displayed similar phenotype to the wild type rice, supporting a role for OsACBP6 in the maintenance of the acylCOA pool and ROS homeostasis. Furthermore, quantification of plant hormones supported the findings observed in the transcriptome and an increase in jasmonic acid level occurred in osacbp6.

Conclusions: In summary, OSACBP6 appears to be required for the efficient utilization of acyl-CoAs. Disruption of OsACBP6 compromises growth and led to provoked defense response, suggesting a correlation of enhanced acylCoAs content with defense responses.

Keywords: Acyl-CoA esters, Acyl-CoA-binding protein, Jasmonic acid, Lipid metabolism, Peroxidases, Reactive oxygen species

\section{Background}

The primary role of acyl-coenzyme A (CoA) esters is to act as intermediates in lipid synthesis and breakdown (Neess et al. 2015). De novo synthesized fatty acids in the chloroplasts are transferred in the form of $\mathrm{C} 16: 0-\mathrm{CoA}$ and $\mathrm{C} 18: 1-\mathrm{CoA}$ to the endoplasmic

\footnotetext{
* Correspondence: mengwei@nefu.edu.cn

${ }^{1}$ Key Laboratory of Saline-alkali Vegetation Ecology Restoration (Northeast Forestry University), Ministry of Education, Harbin 150040, China

${ }^{2}$ College of Life Science, Northeast Forestry University, Harbin 150040, China

Full list of author information is available at the end of the article
}

reticulum (ER) for phospholipid and triacylglycerol (TAG) synthesis (Li-Beisson et al. 2013). In seeds following imbibition, TAG is rapidly mobilized to support successful germination and seedling establishment via a series of catabolic pathways (Graham 2008; Li-Beisson et al. 2013). Rapid TAG turnover also occurred in vegetative tissues (Kelly et al. 2013). First, TAG is hydrolyzed by lipases to free fatty acids, followed by activation to CoA esters (Li-Beisson et al. 2013). Subsequently, fatty acyl-CoAs are imported into the peroxisomes by the peroxisomal ATPbinding cassette $(\mathrm{ABC})$ transporter protein COMATOSE

\section{Springer Open}

(๑) The Author(s). 2020 Open Access This article is licensed under a Creative Commons Attribution 4.0 International License, which permits use, sharing, adaptation, distribution and reproduction in any medium or format, as long as you give appropriate credit to the original author(s) and the source, provide a link to the Creative Commons licence, and indicate if changes were made. The images or other third party material in this article are included in the article's Creative Commons licence, unless indicated otherwise in a credit line to the material. If material is not included in the article's Creative Commons licence and your intended use is not permitted by statutory regulation or exceeds the permitted use, you will need to obtain permission directly from the copyright holder. To view a copy of this licence, visit http://creativecommons.org/licenses/by/4.0/. 
(CTS)/PEROXISOME DEFECTIVE 3 (PED3)/PEROXISOMAL ABC TRANSPORTER 1 (PXA1), which possesses thioesterase activity that hydrolyzes fatty acyl-CoAs to free fatty acids and CoA as part of the transport process (De Marcos et al. 2013). Once inside the peroxisome, the formation of long-chain acyl-CoA esters is catalyzed by long-chain acyl-CoA synthetase (Li-Beisson et al. 2013). Following a series of enzymatic $\beta$-oxidation reactions by acyl-CoA oxidases, multifunctional proteins, and thiolases, fatty acids are degraded to acetyl-CoA for further use in gluconeogenesis and respiration (Li-Beisson et al. 2013).

The intrinsic nature of acyl-CoA is amphipathic (Neess et al. 2015). Although the cellular concentration of acylCoAs ranges from several $\mu \mathrm{M}$ to several hundred $\mu \mathrm{M}$, the concentration of free unbound acyl-CoAs is unknown or could be extremely low (Neess et al. 2015). Usually, acylCoAs are bound to membrane lipids or proteins with high affinities, so that the concentration is strictly controlled to below the critical micelle concentration to avoid detergent effects that disrupt the membrane (Neess et al. 2015). The small (10-kD) acyl-CoA-binding proteins (ACBPs) are known to bind acyl-CoA esters (Knudsen et al. 2000). Each ACBP has a conserved acyl-CoA-binding domain that allows the ACBPs to bind acyl-CoA esters, which can then form a cellular acyl-CoA pool and protect acyl-CoAs against hydrolysis ( $\mathrm{Du}$ et al. 2016). Considering that ACBPs bind acyl-CoAs with high affinities and broad ligand selectivity (C12-C26), ACBPs are believed to be the predominant acyl-CoA carriers/transporters (Knudsen et al. 2000; Neess et al. 2015; Lung and Chye 2016a, b; Guo et al. 2017).

In plants, ACBPs are highly conserved throughout the evolution of land plants and are divided into four classes (Classes I-IV) based on domain architecture (Meng et al. 2011). The functions of Arabidopsis ACBPs (AtACBPs) in development and stress responses have been extensively investigated (Du et al. 2016; Lung and Chye 2016b, 2019). Much evidence indicates that AtACBPs mediate multiple aspects of plant physiology by regulating lipid metabolism in Arabidopsis ( $\mathrm{Du}$ et al. 2016; Lung and Chye 2016b, 2019). There is only a single 10$\mathrm{kD}$ Class I ACBP member in Arabidopsis, namely AtACBP6, and AtACBP6 has been reported to be a cytosolic protein (Chen et al. 2008). AtACBP1 and AtACBP2 are Class II paralogues of each other and have been proposed to function in the ER in acyl-CoA pool formation and acyl-CoA/lipid trafficking between the plasma membrane and the ER during early embryogenesis (Chen et al. 2010). Furthermore, the overexpression of AtACBP1 in Arabidopsis resulted in the accumulation of phosphatidic acid (PA) during seed germination and seedling development following abscisic acid (ABA) treatment (Du et al. 2013). Similar PA accumulation in AtACBP1 overexpressors occurred during freezing treatment ( $\mathrm{Du}$ et al. 2010). The interaction between AtACBP1 and phospholipase D $\alpha 1$ (PLD $\alpha 1$ ), a phospholipase that generates PA, played an essential role in both studies (Du et al. 2010; Du et al. 2013). In addition, the interaction between AtACBP1 and STEROL C4-METH YL OXIDASE1 (SMO1) regulated both fatty acid and sterol homeostasis, and in turn modulated the expression of homeodomain-leucine zipper IV transcription factors (TFs) (Lung et al. 2018). The overexpression of another member, Class III AtACBP3, accelerated leaf senescence increasing the acyl-CoA pool and phosphatidylethanolamine (PE) content (Xiao et al. 2010). The variation in AtACBP3 level and PE composition between AtACBP3-overexpressors and AtACBP3-knockout mutants indicated that AtACBP3 binds and regulates PE in vivo (Xiao et al. 2010). Furthermore, the recombinant proteins of the three cytosolic AtACBPs, comprising Class IV members (AtACBP4 and AtACBP5), and Class I AtACBP6, were reported to bind C16:0-CoA, C18:1CoA, C18:2-CoA, and C18:3-CoA with different affinities (Hsiao et al. 2014a). The double mutants and the triple mutant of these three cytosolic AtACBPs were altered in acyl-CoA composition and displayed high ABA sensitivity during seed germination (Hsiao et al. 2014a). The decrease in oil bodies and decline in germination rate of acbp4acbp5acbp6 pollen suggested important roles for the cytosolic AtACBPs in pollen lipid metabolism (Hsiao et al. 2015).

Thus far, the functions of plant ACBPs have been widely elucidated in the eudicots, such as Arabidopsis and Brassica napus, although there have been many reports on the characterization of ACBP family members from other plant species, such as Oryza sativa, Agave americana, Vernicia fordii, Vitis vinifera, Helianthus annuus, Gossypium hirsutum, Jatropha curcas, and Elaeis guineensis ( $\mathrm{Du}$ et al. 2016; Raboanatahiry et al. 2018; Liao et al. 2019; Amiruddin et al. 2020). Other than Arabidopsis and Brassica napus, the functions of ACBPs from other plant species have been mostly investigated using transgenic Arabidopsis (Takato et al. 2013; Meng et al. 2014; Panthapulakkal Narayanan et al. 2019). Previously, we have reported a peroxisome-localized rice Class IV ACBP, OsACBP6, which is currently the only plant ACBP identified to be localized at the peroxisome (Meng et al. 2014). The overexpression of OsACBP6 in the Arabidopsis $\beta$-oxidation-deficient mutant pxa1 rescued indole-3-butyric acid (IBA) sensitivity and jasmonic acid (JA) production after wound treatment, suggesting that OsACBP6 may be involved in peroxisomal $\beta$-oxidation (Meng et al. 2014). In this study to investigate the function of the peroxisomal OsACBP6 in rice, we analyzed a T-DNA insertional mutant of OsACBP6 (osacbp6) that demonstrated its reduction in root meristem activity and leaf growth. The results from 
comprehensive acyl-CoA and lipid profiling indicated that disruption of OsACBP6 compromised the maintenance of the acyl-CoA pool and altered lipid composition in leaves. By comparative transcriptomic analysis of the shoots/leaves and roots from various growth stages, differentially-expressed genes were identified in osacbp6. Gene ontology (GO) enrichment analysis and functional classification provided insights into the function of OsACBP6 in the oxidative stress response. Accumulation of reactive oxygen species (ROS) and elevation of the JA was evident in osacbp6.

\section{Results}

The Rice osacbp6 Mutant Displayed Growth Retardation DNA sequence analysis of the osacbp6 mutant indicated that the T-DNA had inserted into the 11th exon of OsACBP6 as shown in Fig. 1a. The location of the T-
DNA insertion in OsACBP6 was confirmed by PCR using a combination of gene-specific primers, ML2066, and ML2067, as well as T-DNA left border primers 2717LB and ML2067 (Fig. 1b). Semiquantitative RT-PCR using gene-specific primers ML1050 and ML1051 confirmed the absence of OsACBP6 expression in the mutant (Fig. 1c). The homozygous osacbp6 line was then used in subsequent experiments.

As OsACBP6 had been proposed to play a role in fatty acid $\beta$-oxidation through its acyl-CoA binding ability (Meng et al. 2014), osacbp6 was examined for the typical phenotypes related to defects in $\beta$-oxidation. When osacbp 6 and the wild type were tested in seed germination and seedling establishment in water, both germinated at about the same time but the development of the roots of osacbp6 seedlings was repressed with primary root reduction around $40 \%$ (Fig. $1 \mathrm{~d}$ and e). When

a

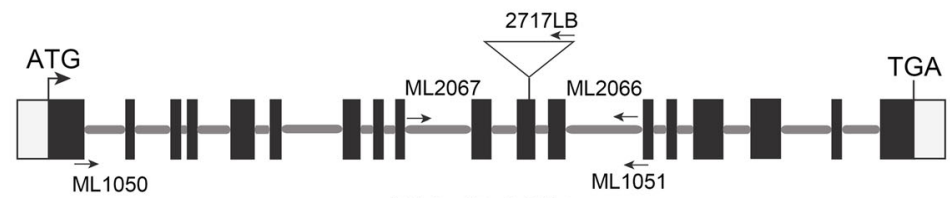

PFG_1B-14906

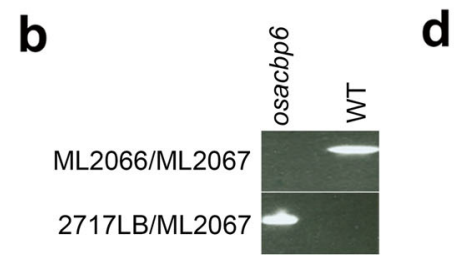

C
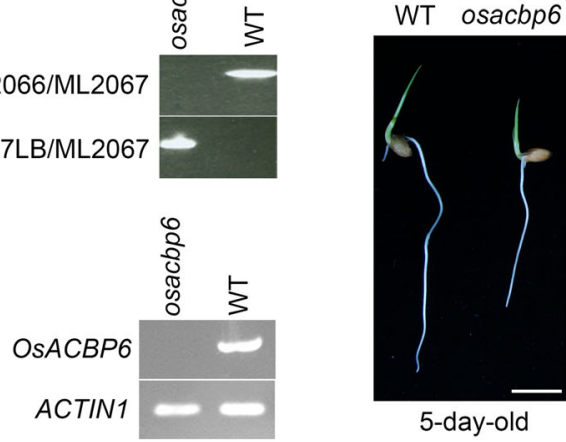

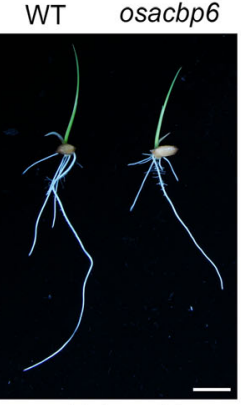

7-day-old

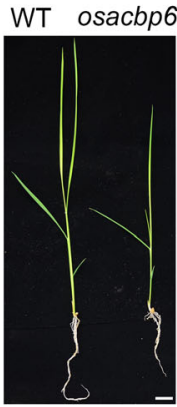

21-day-old
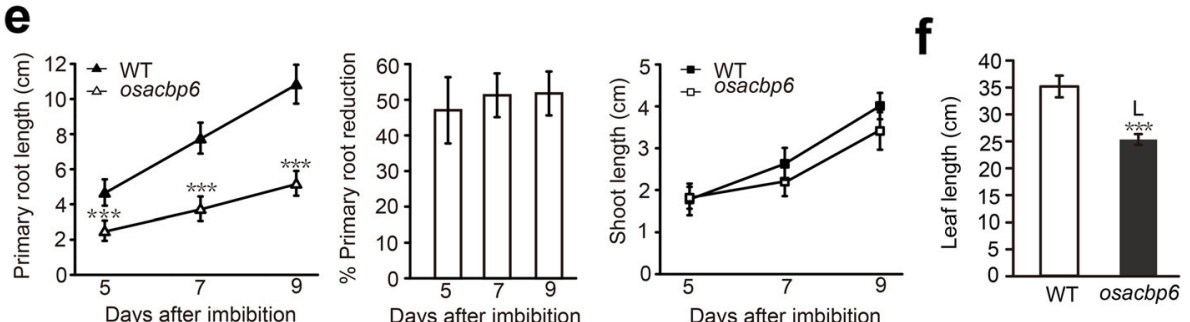

Fig. 1 Characterization of the rice osacbp6 mutant. a T-DNA insertion in OSACBP6, and primer locations used for PCR genotyping. Black and grey boxes indicate coding and untranslated regions, respectively. b PCR genotyping of osacbp6. Primer combinations ML2066/ML2067 (top gel) and 2717LB/ML2067 (bottom gel) in PCR to identify osacbp6 homozygous mutant. c Semi-quantitative RT-PCR showing the knockout of OsACBP6 in osacbp6. ACTIN1 served as a control. d Growth of wild type (WT, Oryza sativa var. japonica cv. Dongjin) and osacbp6. Images from left to right represent 5-, 7-day-old seedlings grown in water, and 21-day-old soil-grown seedling. Bars, $1 \mathrm{~cm}$. e The primary root length (left) and shoot length (right) comparison between WT and osacbp6. Primary root reduction of osacbp6 is shown in the middle. Values are mean \pm SD $(n=25)$. $\mathbf{f}$ Comparison of the leaf length of 21-day-old soil-grown seedlings between WT and osacbp6. Values are mean \pm SD $(n=5)$. Asterisks indicate significant differences between WT and osacbp6 as evaluated by Student's t-tests: *** $P 0.001$ 
osacbp6 and the wild type were grown in soil, osacbp6 root development was retarded (around 30\% primary root reduction), but not as severe as previously observed in water (Fig. S1). In both situations, there was no obvious difference in the length of the shoots between osacbp6 and the wild type at the early stage of the seedling development (Fig. 1e, Fig. S1b). However, the leaf length of 21day-old osacbp6 was significantly shorter than the wild type with a reduction of around 25\% (Fig. 1d and f). Furthermore, osacbp 6 grains were reduced in length but remained unchanged in width in comparison to the wild type (Fig. S2a). Lastly, given that the product of IBA $\beta$-oxidation is indole-3-acetic acid (IAA) which has growth inhibition effect, the IBA sensitivity of osacbp6 was examined to investigate whether $\beta$-oxidation process was blocked in osacbp6. Reduced primary root elongation of osacbp6 after IBA treatment indicated that osacbp6 was sensitive to growth inhibition by IBA (Fig. S2b), suggesting the IBA $\beta$-oxidation was not blocked in osacbp6. Taken together, from phenotypic observations it appears that $\beta$ oxidation was not severely affected due to the loss in OsACBP6.

When the osacbp6 mutant was complemented, the three independent complemented lines (designated as osacbp 6-C1, osacbp6-C2, and osacbp6-C4) displayed normal growth similar to the wild type, including the primary root length, 21-day-old leaf length, and grain length (Fig. 2, Fig. S3). Moreover, the phenotype of seedlings from hemizygous complemented line osacbp6-C4 were examined. In contrast with wild type normal growth of primary root and leaves, seedlings from hemizygous complemented line contained both wild type growth (168) and retarded growth (51) of roots and leaves with a $3: 1$ segregation ratio $\left(x^{2}=0.34\right)$. These findings confirmed that growth arrest was caused by the loss of OsACBP6.

In addition, expression information from the Rice eFP Browser (http://bar.utoronto.ca/efprice/cgi-bin/efpWeb. cgi) showed that OsACBP6 is highly expressed at seedling roots, young leaf and mature leaf (Fig. S4), suggesting OsACBP6 may have important roles in these tissues. Therefore, the root meristem activity was further investigated, 5-ethynyl-2'-deoxyuridine (EdU) staining indicated that reduced EdU labeling was observed in the root tip of osacbp6 but not in the complemented line (Fig. 3a-d), indicating that cell proliferation in the root meristem affected by the loss of OsACBP6 could be complemented by the OsACBP6 ORF. On the other hand, observation of leaf growth showed that the emergence of the third leaf of osacbp 6 was one day later than the wild type. When the third leaf of osacbp 6 emerged from the leaf sheath, the third leaf length of the wild type and the complemented line was about $6 \mathrm{~cm}$ longer than osacbp6 (Fig. 3e). Meanwhile, the leaf elongation rate of osacbp6 was significantly lower than the wild type and the complemented line (Fig. 3f). These results indicated both root and the leaf development were affected in the osacbp 6 mutant and function was restored upon complementation.

\section{Changes in Acyl-CoA and Lipid Profiles in osacbp6}

To gain an insight into the relationship between the loss of OsACBP6 and compromised growth, the acyl-CoA profiles in osacbp6 was determined. The absence of OsACBP6 function is expected to disrupt fatty acid $\beta$ oxidation and result in the accumulation of long-chain acyl-CoAs. To test this hypothesis, a comparison was made amongst the acyl-CoA content in 21-day-old leaves of osacbp6, the wild type and the complemented line. As revealed in acyl-CoA measurements, the content of acyl-CoAs in osacbp 6 was significantly higher than the wild type and complemented line (osacbp6-C4) (Fig. 4a). Amongst all tested acyl-CoA esters, C18:3-CoA was notably enriched in the leaves of 21-day-old osacbp 6 in contrast to the wild type and osacbp6-C4 (Fig. 4b). When compared with osacbp6, the level of C14:0-CoA, C18:0-CoA and C18:1-CoA showed a decrease in osacbp6-C4 (Fig. 4b). In contrast to wild type, C18:2CoA had significantly declined in osacbp6-C4 while C16: 0 -CoA remained unchanged in all samples (Fig. 4b). These findings indicate that loss of OsACBP6 had likely compromised the maintenance of an acyl-CoA pool, particularly in the utilization of C18:3-CoA.

When the lipid composition of 21-day-old leaves was compared amongst osacbp6, the wild type, and the complemented line, few differences were apparent in all samples. The total amounts of membrane lipid species analyzed including monogalactosyldiacylglycerol (MGDG), digalactosyldiacylglycerol (DGDG), phosphatidylglycerol (PG), phosphatidylcholine (PC), PE, PA, phosphatidylserine (PS), and phosphatidylinositol (PI) remained unchanged (Fig. 4c, Fig. S5). On the other hand, in comparison with osacbp6, the total storage lipids TAG content significantly declined in osacbp6-C4 (Fig. 4d, Dataset S1), although difference between the wild type and osacbp 6 was not significant. However, analysis of TAG molecular species revealed that TAG molecules 52:4(18:1), 54:8(18:3), 54:8(18:2), 54:7(18:1), 54: $6(18: 1)$, and $56: 7(18: 3)$ were significantly elevated in osacbp6 in comparison with the wild type (Fig. 4e). In contrast to osacbp6, the complemented line showed significant decrease in TAG56 molecules 56:5(18:3), 56: $6(18: 3)$ and $56: 7(18: 3)$, most of the TAG54 molecules (54:9(18:3), 54:8(18:3), 54:8(18:2), 54:7(18:3), 54:7(18:2), $54: 7(18: 1), 54: 6(18: 3), 54: 6(18: 2), 54: 6(18: 1), 54: 5(18: 3)$, $54: 5(18: 2), 54: 5(18: 1), 54: 4(18: 3), 54: 4(18: 2), 54: 4(18: 1)$, 54:3(18:2)) and several TAG52 molecules (Dataset S1). Meanwhile, the complemented line when compared with 
a

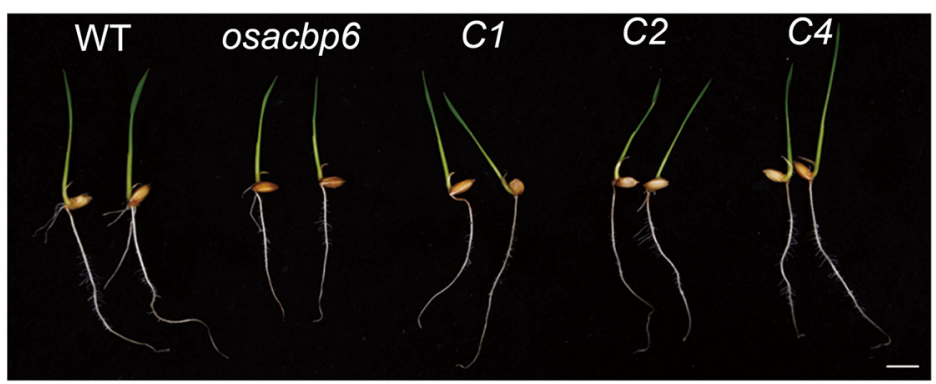

b

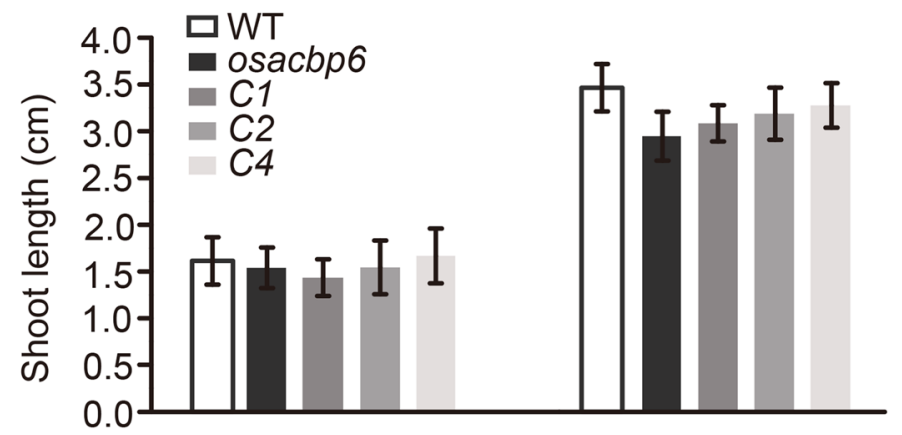

C
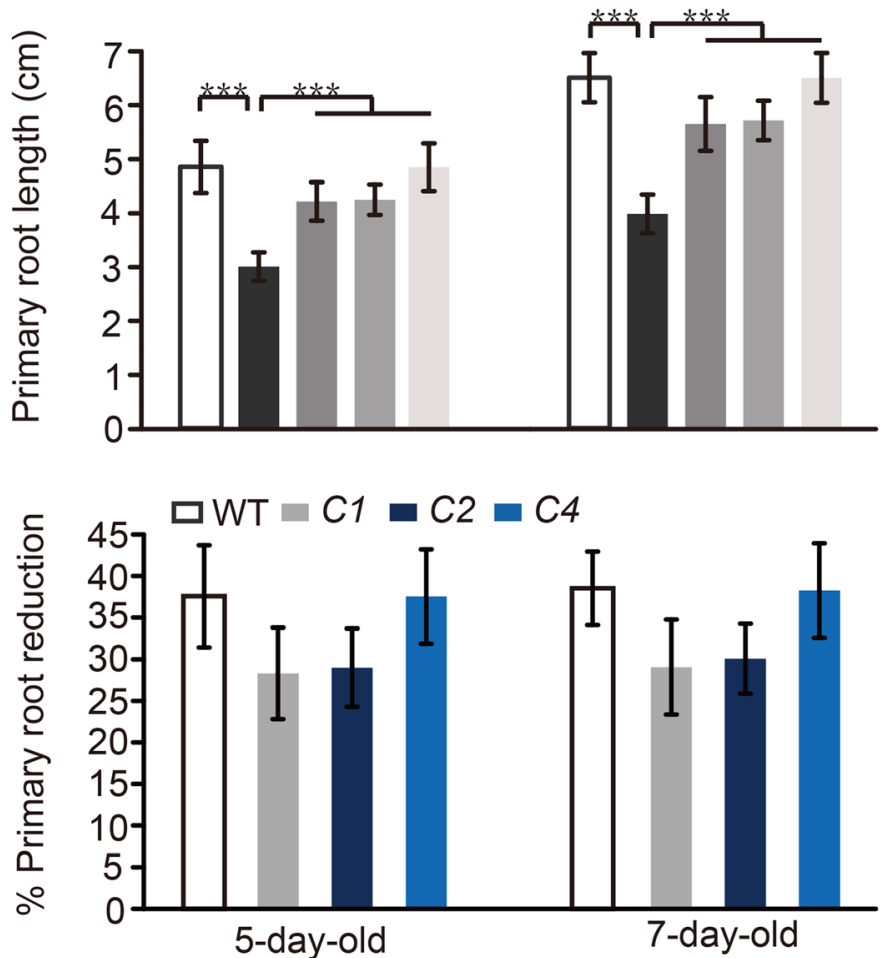

Fig. 2 Recovery in growth retardation of the rice osacbp6 mutant by complementation of OsACBP6. a Growth of 7-day-old seedlings of wild type (WT), osacbp6 and complemented lines osacbp6-C1 (C1), osacbp6-C2 (C2) and osacbp6-C4 (C4). Bar, 1 cm. b Shoot length of WT, osacbp6, C1, C2 and C4. Values are means \pm SD $(n=10)$. c Primary root length of WT, osacbp6, C1, C2, and C4 (upper panel) and primary root reduction of osacbp6 relative to $\mathrm{WT}, \mathrm{C1}, \mathrm{C2}$, and C4 (lower panel). Values are means $\pm \mathrm{SD}(n=10)$. Asterisks indicate significant differences as evaluated by Student's t-tests: ***P $<0.001$. WT, Oryza sativa var. japonica cv. Dongjin

the wild type, exhibited lower amounts of TAG molecules 52:7(18:3), 52:5(16:0), 52:3(18:3), 52:3(18:2), 54: 9(18:3), 54:8(18:2), 54:6(18:3), 56:6(18:3), and 56:5(18:3) (Fig. 4e, Dataset S1).
Comparative Transcriptomic Analysis between osacbp6 and the Wild Type

To further analyze the potential role of OsACBP6 in growth regulation, a comparative transcriptomic analysis 

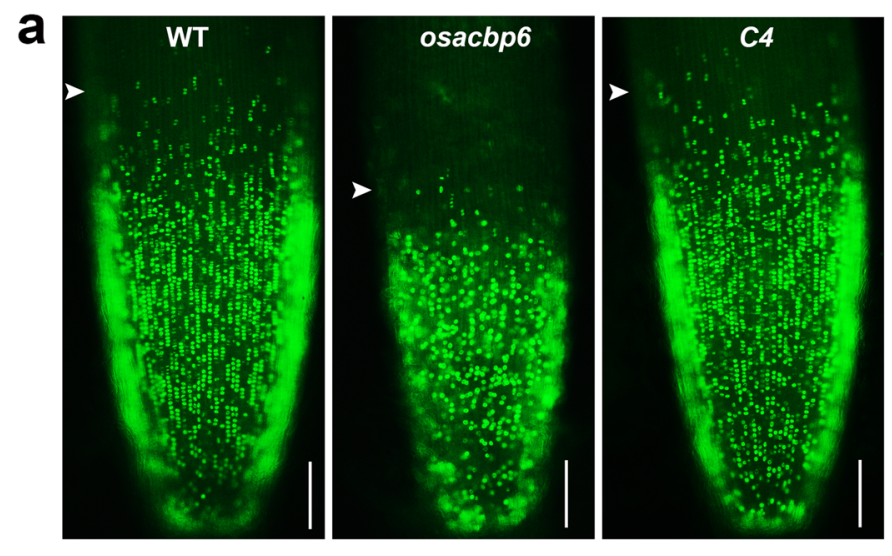

e
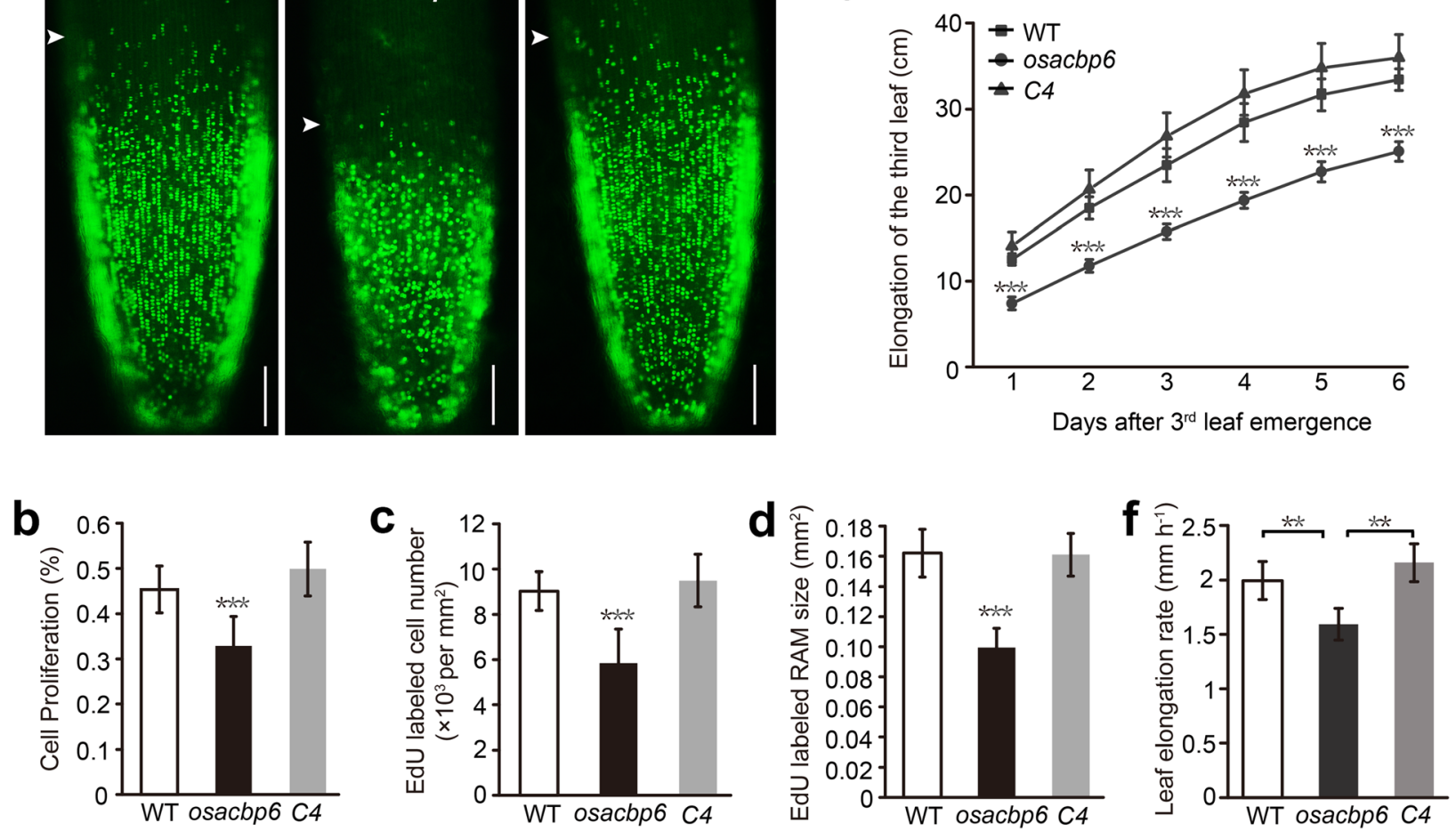

Fig. 3 Reduced root meristem activity and leaf elongation in the rice osacbp6 mutant. a Representative cell proliferation in the root tip cells of 5day-old wild-type (WT), osacbp6 and complemented line osacbp6-C4 (C4) seedlings visualized by 5-ethynyl-2'-deoxyuridine (EdU) staining. Bars, $100 \mu \mathrm{m}$. Arrowheads indicate the border of EdU staining. $\mathbf{b}$ - d Relative quantification of the proliferating cells labeled with EdU, including the percentage of cell proliferation calculated as the ratio of EdU/DAPI (b), average proliferating cell number (c), and EdU-labeled root apical meristem size (d). Values are means \pm SD $(n=10)$. e and $\mathbf{f}$ Measurement of the length of the third leaf $(\mathbf{e})$ and leaf elongation rate $(\mathbf{f})$. Values are means \pm SD $(n=5)$. Asterisks indicate significant differences as evaluated by Student's $t$-tests: ${ }^{* *} P<0.01,{ }^{* * *} P<0.001$. DAPI, 4',6-Diamidino-2Phenylindole; WT, Oryza sativa var. japonica cv. Dongjin

was performed between $o s a c b p 6$ and the wild type at different growth stages (Dataset S2, S3, S4, S5, S6, S7). Differentially expressed genes (DEGs) in osacbp6 were associated with primary metabolic processes, including the light reaction, cell wall and lipid metabolism; and secondary metabolic processes related to terpenes, flavonoids, and phenylpropanoids. In osacbp6, genes involved in fatty acid synthesis and elongation, phospholipid synthesis, and lipid degradation appeared to be affected (Fig. S6). However, the key enzymes in $\beta$-oxidation, such as acyl-CoA oxidase, multifunctional protein, and 3ketoacyl-CoA thiolase were not differentially expressed in osacbp6 (Fig. S6). Furthermore, most of the DEGs were responsive to biotic stress (Fig. S7a). Compared with the wild type, various categories related to biotic stress were differentially expressed in $o s a c b p 6$, including plant hormone signaling, PR proteins, cell wall, proteolysis, signaling, TFs, heat shock proteins, secondary metabolites. DEGs associated with defense hormone (ABA, JA, salicylic acid (SA), and ethylene) and growth hormone (auxin, gibberellin (GA), brassinosteroid (BR) and cytokinin) (Fig. S7b) and differentially expressed TFs
(Fig. S7c) are displayed in Dataset S8 and S9, respectively. Amongst differentially expressed TFs, basic helixloop-helix (bHLH) was strongly activated in the young seedlings, especially in 5-day-old roots (Fig. S7c). In 21day-old leaves, WRKY was more activated than in the other samples (Fig. S7c).

Significantly enriched Gene Ontology (GO) categories were illustrated in Dataset S2. The GO term oxidation reduction was the most enriched in young seedlings and was common to all samples, except for the lack of a significantly enriched GO term in 7-dayold shoots. Another significantly enriched category was a response to oxidative stress that was only evident in the downregulated DEGs, and solely consisted of putative peroxidase precursor genes (class III peroxidase). Gene expression of peroxidases was verified by quantitative real-time RT-PCR (qRT-PCR). In comparison to the wild type, eight peroxidases were downregulated in 7-day-old osacbp6 roots and upregulated in the complemented line (Fig. 5a). In 7day-old shoots and 21-day-old leaves, the number of differentially expressed peroxidase was lower than 7- 
a

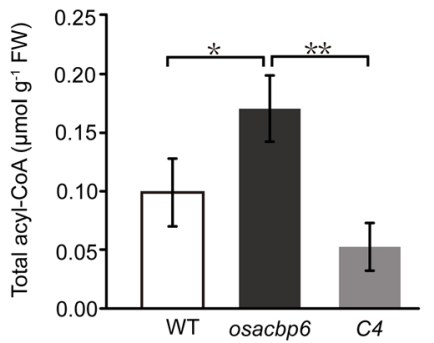

C Membrane lipids

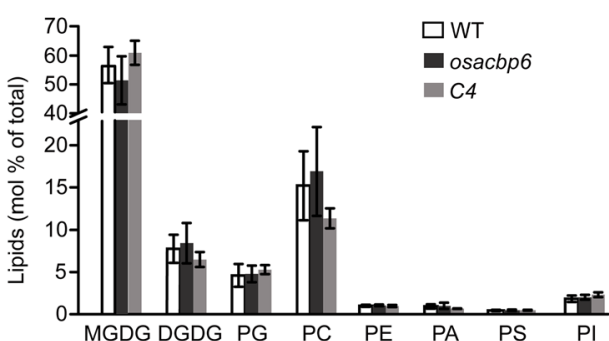

b

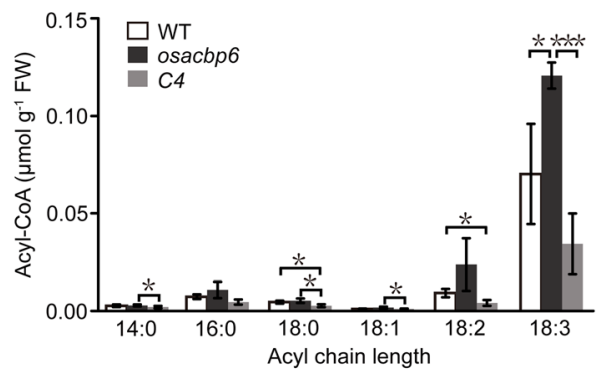

d Storage lipids

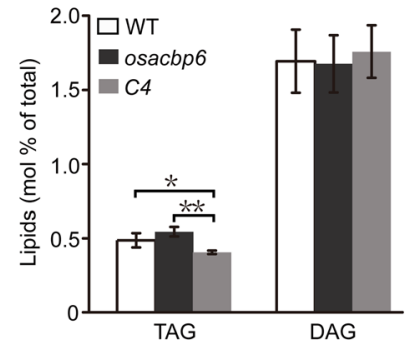

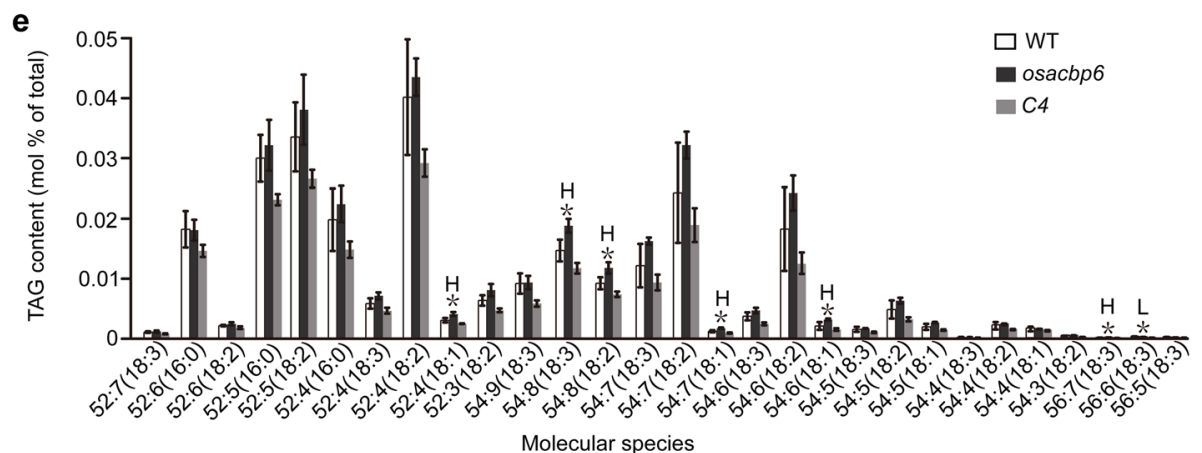

Fig. 4 Acyl-coenzyme A (CoA) and lipid profiles of 21-day-old leaves. a Comparison of total acyl-CoA content of the wild type rice (WT), the osacbp6 mutant and the complemented line osacbp6-C4 (C4). b The concentration of different acyl-CoA species. c Membrane lipid content (mol $\%$ of total lipids analyzed). Values are means \pm SD $(n=3)$. d Storage lipid content (mol \% of total lipids analyzed). Values are means \pm SD ( $n=3$ ). e The abundance of selected individual TAG molecular species (mol \% of total) in 21-day-old leaves of the rice osacbp6 mutant, WT, and C4. Values are means \pm SD $(n=3)$. H, value of osacbp6 is higher than WT; L, value of osacbp6 is lower than WT. Values of C4 are all significantly lower than osacbp6 as evaluated by Student's t-tests. Asterisks indicate significant differences as evaluated by Student's t-tests: ${ }^{*} P<0.05$, ** $P<0.01$, ${ }^{* *} P<0.001$. FW, fresh weight; WT, Oryza sativa var. japonica cv. Dongjin. DAG, Diacylglycerol; TAG, Triacylglycerol; MGDG,

Monogalactosyldiacylglycerol; DGDG, Digalactosyldiacylglycerol; PC, Phosphatidylcholine; PG, Phosphatidylglycerol; PA, Phosphatidic acid; PI, Phosphatidylinositol; PE, Phosphatidylethanolamine; PS, Phosphatidylserine

day-old roots. In particular, LOC_OsO3g13180 and LOC_Os04g59190 had decreased in osacbp6 in contrast to an increase in the complemented line in all test samples (Fig. 5a). In addition, expression information from the Rice eFP Browser (http://bar.utoronto. ca/efprice/cgi-bin/efpWeb.cgi) indicated that most of these eight peroxidases are highly expressed in roots (Fig. S8), suggesting probable significant roles in roots. Furthermore, the peroxidase activities were compared amongst osacbp6, the wild type, and the complemented line. In comparison with the wild type, the peroxidase activities in osacbp6 decreased $25 \%$ in 7 -day-old roots, $17 \%$ in 7 -day-old shoots, and $17 \%$ in 21-day-old leaves (Fig. 5b). As expected, the level of peroxidase activities in the complemented line remained similar to the wild type with the exception of an increase in 7-day-old shoots (Fig. 5b). Given that peroxidases are bifunctional enzymes that can oxidize substrates at the expense of $\mathrm{H}_{2} \mathrm{O}_{2}$ but also produce ROS (Passardi et al. 2004), an abundant decline in the expression of peroxidases and reduced peroxidase activities suggest that ROS homeostasis in osacbp6 is perturbed. Taken together, a loss in OsACBP6 had resulted in transcriptional changes in the expression of genes related to redox, $\mathrm{H}_{2} \mathrm{O}_{2}$ scavenging, and defense responses. 

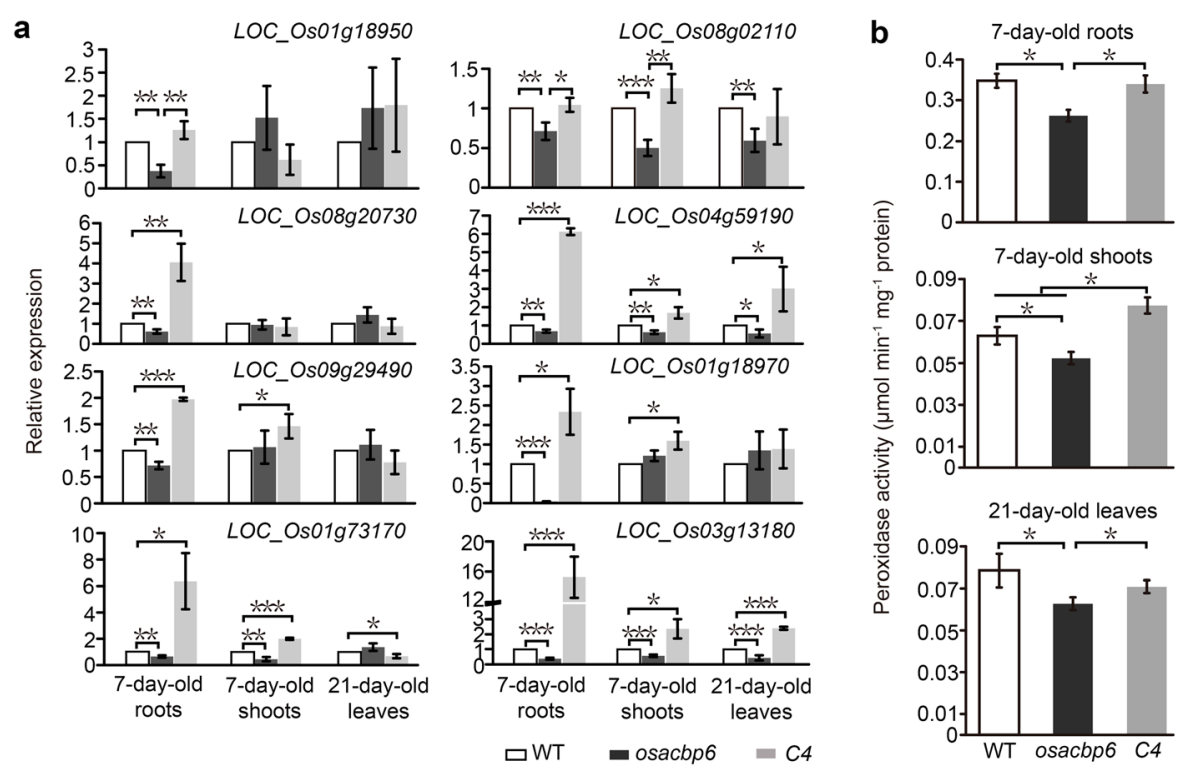

C
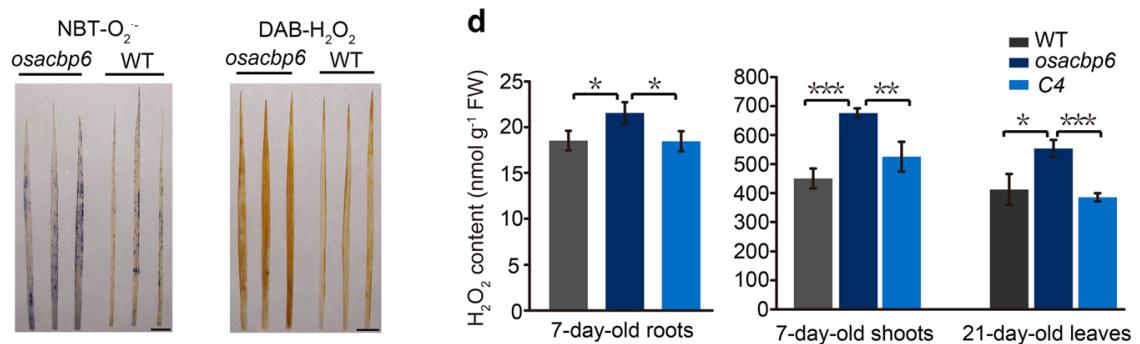

Fig. 5 Disruption of reactive oxygen species homeostasis in the rice osacbp6 mutant. a Relative expression of genes encoding class III peroxidases. Values are mean \pm SD $(n=3)$. b Comparison of peroxidase activities of the roots and shoots of 7-day-old seedlings and leaves of 21day-old wild type (WT), osacbp6 and complemented line osacbp6-C4 (C4). Values are means \pm SD $(n=3)$. c Accumulation of superoxide anion $\left(\mathrm{O}_{2}^{-}\right)$and hydrogen peroxide $\left(\mathrm{H}_{2} \mathrm{O}_{2}\right)$ in the leaf blades of osacbp6. Leaf blades of 21-day-old WT and osacbp6 were subjected to nitroblue tetrazolium (NBT) staining to detect $\mathrm{O}_{2}{ }^{--}$or 3,3'-diaminobenzidine tetrahydrochloride (DAB) staining to detect $\mathrm{H}_{2} \mathrm{O}_{2}$ in the dark for 3 and $24 \mathrm{~h}$, respectively. Bars, $1 \mathrm{~cm}$. $\mathbf{d ~ H} \mathrm{H}_{2} \mathrm{O}_{2}$ content in the roots and shoots of 7-day-old seedlings and leaves of 21-day-old WT, osacbp6 and C4. Values are means \pm SD $(n=3)$. Asterisks indicate significant differences as evaluated by Student's $t$-tests: ${ }^{*} P<0.05,{ }^{*} P<0.01,{ }^{* *} P<0.001$. WT, Oryza sativa var. japonica cv. Dongjin

\section{ROS Homeostasis Is Perturbed in osacbp6}

To examine whether the ROS levels were altered in osacbp6, superoxide anion $\left(\mathrm{O}_{2}{ }^{--}\right)$and $\mathrm{H}_{2} \mathrm{O}_{2}$ contents were examined. The blue and brown coloration in 21day-old osacbp 6 leaf blades indicated the accumulation of $\mathrm{O}_{2}{ }^{--}$and $\mathrm{H}_{2} \mathrm{O}_{2}$, respectively (Fig. $5 \mathrm{c}$ ). Furthermore, $\mathrm{H}_{2} \mathrm{O}_{2}$ was quantified in osacbp6, the wild type, and the complemented line (Fig. $5 \mathrm{~d}$ ). The $\mathrm{H}_{2} \mathrm{O}_{2}$ levels in the root and shoot of 7-day-old osacbp6 seedling and the leaves of 21-day-old osacbp6 were significantly higher than the wild type and complemented line. Meanwhile, there was no significant difference between the wild type and complemented line suggesting the restoration of OsACBP6 function in the latter.

As OsACBP6 was localized at the peroxisomes (Meng et al. 2014), and $\mathrm{H}_{2} \mathrm{O}_{2}$ overaccumulated in osacbp6, peroxisomal ROS scavenging was next explored. Given that plant peroxisomes employ two major enzymatic antioxidant systems, catalase (CAT) and ascorbate peroxidase (APX)/ monodehydroascorbate reductase (MDAR) system, to detoxify the $\mathrm{H}_{2} \mathrm{O}_{2}$ generated by $\beta$-oxidation (Eastmond 2007), the expression of $A P X, M D A R$, and $C A T$ was examined in osacbp6, the wild type and complemented line by qRT-PCR (Fig. 6). In comparison to the wild type, there was no significant difference in the expression of the eight $A P X$ genes in osacbp6, including peroxisomal localized OsAPX3 and OsAPX4 (Kaur and $\mathrm{Hu}$ 2011). The expression of five $M D A R$ genes was examined. Except LOC_Os08g05570, the rest four $M D A R$ genes are all peroxisomal localized (Kaur and $\mathrm{Hu}$ 2011). Two of the five MDAR genes was enhanced in osacbp6. In particular, LOC_Os08g44340 was induced in osacbp 6 but repressed in the complemented line. Also, the expression of one of the three CAT genes was slightly elevated. Hence, despite $\mathrm{H}_{2} \mathrm{O}_{2}$ accumulation in osacbp6, the peroxisomal ROS scavenging system did not seem to be activated. Moreover, measurements of APX, MDAR and 


\section{a}
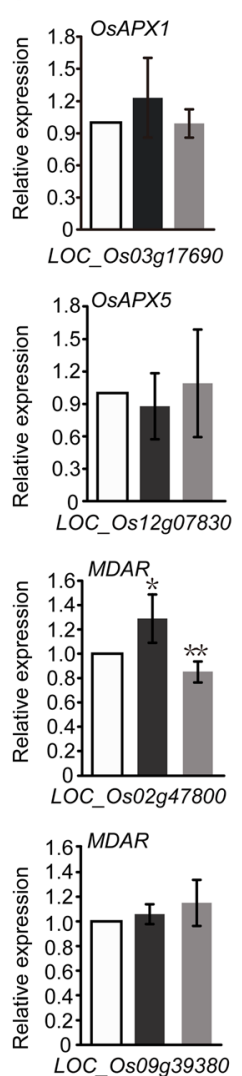
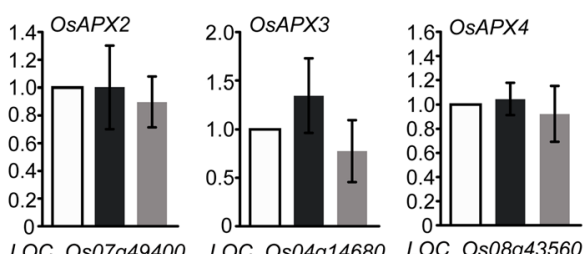

b
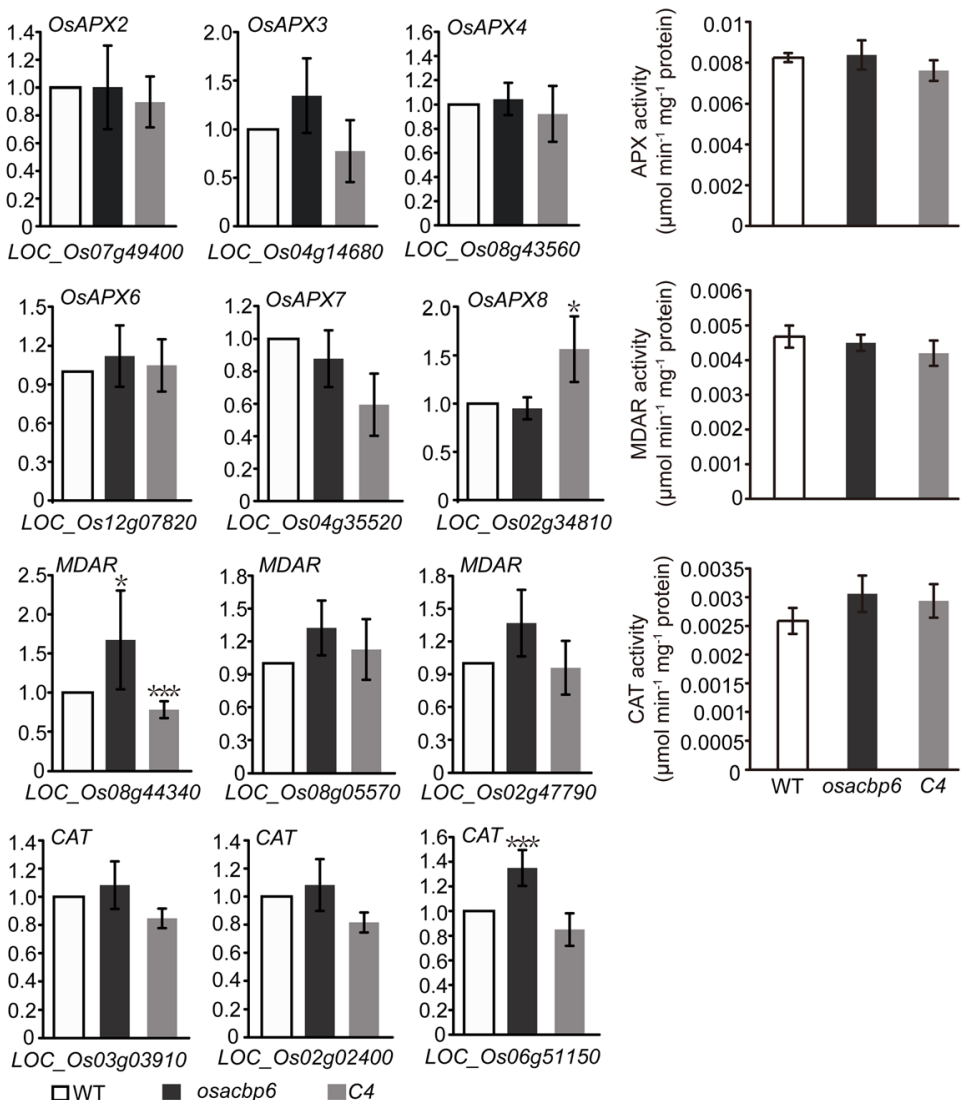

Fig. 6 The expression levels and activities of rice genes associated with reactive oxygen species scavenging. a Relative expression in the leaves of 21-day-old wild type rice (WT), osacbp6 and complemented lines osacbp6-C4 (C4) were determined by quantitative real time RTPCR (qRT-PCR). Values are means \pm SD $(n=3)$. b Comparison of activities of APX, MDAR and CAT. Enzyme activity was detected from 21day-old leaves of WT, osacbp 6 and C4. Values are means \pm SD $(n=3)$. Asterisks indicate significant differences as evaluated by Student's $t$ tests: ${ }^{*} P<0.05,{ }^{* *} P<0.01,{ }^{* *} P<0.001$. APX, ascorbate peroxidase; MDAR, monodehydroascorbate reductase; CAT, catalase; WT, Oryza sativa var. japonica cv. Dongjin

CAT activities further support that there was no significant difference in peroxisomal ROS scavenging system between osacbp6 and the wild type (Fig. 6b). Above findings suggested that the distribution of $\mathrm{H}_{2} \mathrm{O}_{2}$ may not be confined to the peroxisome.

\section{Intrinsic JA Accumulated in osacbp6}

Arising from an observation in differentially expressed plant hormone-related genes, JA biosynthesis was investigated next to address if it was compromised in osacbp6. Because JA is produced through $\beta$-oxidation in the peroxisomes (Hu et al. 2012) and the overexpression of OsACBP6 in the Arabidopsis pxa1 mutant had rescued JA production after wound treatment (Meng et al. 2014). The intrinsic JA level was significantly elevated in 21-day-old osacbp6 leaves (5.64 $\mathrm{ng} \mathrm{g}^{-1}$ ), five times higher than the wild type $\left(1.08 \mathrm{ng} \mathrm{g}^{-1}\right.$ ) (Fig. 7a). Other plant hormones (SA, IAA and $\mathrm{GA}_{3}$ ) were also enhanced in osacbp6 over the wild type (Fig. 7a). Therefore, measurements of hormone levels indicated that JA and SA production was not blocked in osacbp6.

Subsequently, the expression of genes related to JA biosynthesis and the JA signaling pathway in osacbp6 were examined. JA biosynthesis includes the release of $\alpha$-linolenic acid ( $\alpha$-LeA) from the lipid membrane by phospholipases, oxygenation of $\alpha$-LeA by lipoxygenase or $\alpha$-dioxygenases (DOXs) followed by steps catalyzed by allene oxide synthase (AOS) and allene oxide cyclase (AOC) to yield the JA precursor, cis-12-oxo-phytodienoic acid (OPDA). OPDA is then reduced by OPDA reductase (OPR) and subjected to $\beta$-oxidation to generate JA (Wasternack and Feussner 2018). When the expression of phospholipases D (OsPLD $\alpha 4)$ and lipase EXTRA GLUME 1 (EG1) that function in releasing $\alpha$-LeA (Qi et al. 2011; Cai et al. 2014), OsDOX, OsAOS2, OsAOC, OsOPR3 (Koeduka et al. 2005; Mei et al. 2006; Guo et al. 2014) and transcription factor OsMYC2 that positively regulates the JA-responsive genes (Uji et al. 2016), were 

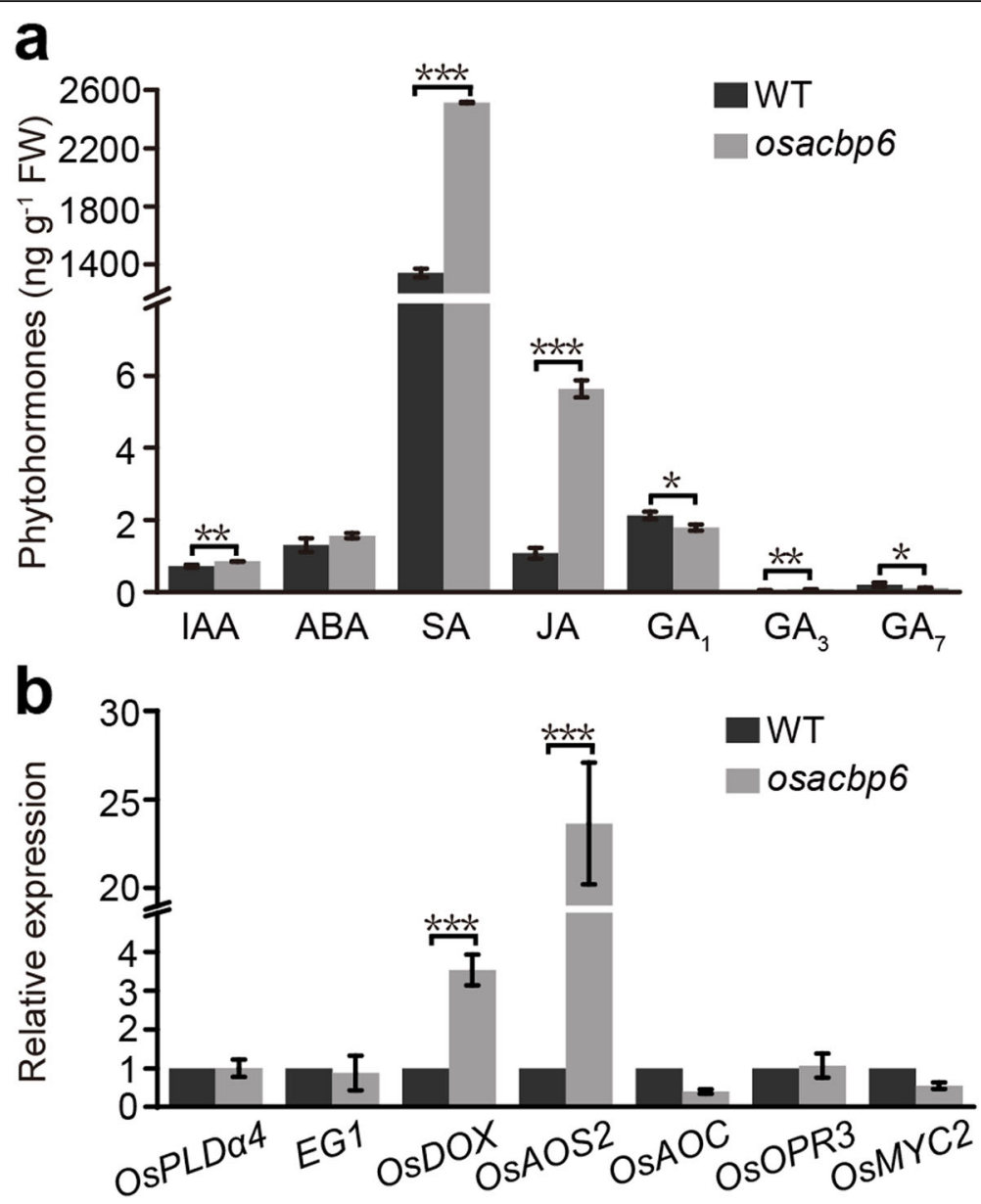

Fig. 7 Alteration of plant hormone levels in the rice osacbp6 mutant. a Measurement of plant hormone content in 21-day-old leaves. b Relative expression of genes related to JA biosynthesis and its signaling pathway. Values are means \pm SD $(n=3)$. Asterisks indicate significant differences between the wild type (WT) and osacbp6 as evaluated by Student's $t$-tests: ${ }^{*} P<0.05,{ }^{*} P<0.01,{ }^{* * *} P<0.001$. WT, Oryza sativa var. japonica cv. Dongjin. IAA, indole-3-acetic acid; ABA, abscisic acid; SA, salicylic acid; JA, jasmonic acid; GA, gibberellin; PLD, phospholipase D; EG1, EXTRA GLUME 1; DOX, a-dioxygenases; AOS, allene oxide synthase; AOC, allene oxide cyclase; OPR, OPDA reductase

examined, only OsDOX and OsAOS2 expression increased in osacbp6, while others remained a similar level to the wild type (Fig. $7 \mathrm{~b}$ ), consistent with transcriptomic data. Given that $O s D O X$ is activated by $\mathrm{H}_{2} \mathrm{O}_{2}$ (Zhu et al. 2013), elevated JA level in osacbp6 would be a consequence of repressed $\mathrm{H}_{2} \mathrm{O}_{2}$ scavenging in osacbp6.

\section{Discussion}

The level and availability of acyl-CoA is strictly controlled by proteins with binding abilities to meet the cellular requirement (Neess et al. 2015). Acyl-CoAs are sequestered and directed toward specific metabolic pathways (Neess et al. 2015). It has been proposed that OsACBP6 is implicated in the formation and regulation of the peroxisomal acyl-CoA pool and donation of acylCoA for $\beta$-oxidation (Meng et al. 2014). This study revealed that the disruption of peroxisomal matrixlocalized OsACBP6 in rice resulted in growth retardation in both roots and leaves as well as smaller grain size, resembling the phenotype of Arabidopsis and barley $\beta$-oxidation dysfunction mutants deficient in the peroxisomal ABC transporter (Zolman et al. 2001; Mendiondo et al. 2014), although the IBA sensitivity remained in osacbp6. The above findings suggest that osacbp 6 was not severely affected in $\beta$-oxidation function. However, increased acyl-CoA levels (specifically C18:3-CoA) and some TAG molecular species content observed in osacbp 6 over the wild type suggest it bears similarity to the Arabidopsis mutants defective in acyl-CoA import (peroxisomal $\mathrm{ABC}$ transporter pxa1/cts/ped3) and activation (peroxisomal long-chain acyl-CoA synthetase lacs6lacs7) and core enzymes of fatty acid $\beta$-oxidation ( $m f p 2$, kat2) (Germain et al. 2001; Fulda et al. 2004; Rylott et al. 2006; Graham 2008). The functions of plant peroxisomal $\mathrm{ABC}$ transporters are highly conserved between eudicot Arabidopsis and monocot barley (Zolman 
et al. 2001; Mendiondo et al. 2014). Although the role of the rice peroxisomal $\mathrm{ABC}$ transporter is yet unclear, two orthologues of Arabidopsis PXA1 co-exists (Kaur and $\mathrm{Hu}$ 2011). Localization of OsACBP6 in the peroxisomal matrix suggests that OsACBP6 would not be able to transfer acyl-CoAs directly from the cytosol into the peroxisome, although OsACBP6 does have a putative $\mathrm{N}$-terminal transmembrane domain. Taken together with findings that recombinant OsACBP6 binds C18:2-CoA and C18:3-CoA with high binding affinities in vitro (Meng et al. 2011), the increased acyl-CoA levels in osacbp 6 and their corresponding decline in the complemented line, support a role for OsACBP6 in the peroxisome most likely associated in the maintenance of a peroxisomal acyl-CoA pool, especially for C18:3-CoA, and to facilitate efficient utilization of acyl-CoAs imported by PXA1 orthologues for subsequent $\beta$-oxidation. Loss of OsACBP6 might disrupt the utilization of C18:3-CoA in the following $\beta$-oxidation and induce a feedback inhibition to the import of $\mathrm{C} 18: 3-\mathrm{CoA}$ into the peroxisomes which might lead to the accumulation of C18:3-CoA in the cytosol. On the other hand, DEGrelated to fatty acids synthesis, phospholipids biosynthesis, and TAG biosynthesis were limited in osacbp6, suggesting loss of OsACBP6 may not increase TAG content. However, it has been proposed that acyl-CoA utilization has a feedback influence on the rate of TAG lipolysis, and the mechanism of acyl-CoA-mediated inhibition of TAG breakdown is not clear (Graham 2008; Quettier and Eastmond 2009). Therefore, in osacbp6, the relationship between acyl-CoA accumulation and an increase in some TAG molecular species content awaits to be further elucidated.

Arabidopsis mutants defective in $\beta$-oxidation-related genes commonly display failure in early seedling establishment due to a block in TAG turnover (Graham 2008). The phenotypic difference between the wild type and these mutants is indistinguishable at the vegetative phase but some of them show abnormal inflorescence later (Richmond and Bleecker 1999; Fulda et al. 2004; Rylott et al. 2006; Wiszniewski et al. 2014). In contrast, as starch in the endosperm is the major energy supply for monocots post-germinative growth, the seedling establishment does not seem to be affected by a deficiency in fatty acid $\beta$-oxidation (Mendiondo et al. 2014; Xu et al. 2017). However, distinguishable phenotypes emerge at the vegetative phase. A rice aim1 mutant appeared as a short root mutant with reduced meristem activity due to blocked SA biosynthesis and reduced ROS level (Xu et al. 2017). By repressing the expression of redox and ROS-scavenging genes and maintaining a proper level of ROS, SA maintains root meristem activity (Xu et al. 2017). In this study, the root meristem activity of osacbp 6 also declined, but unlike aim1, its $\mathrm{H}_{2} \mathrm{O}_{2}$ level in root was elevated. It has been demonstrated that Arabidopsis bHLH TF UPBEAT1 (UPB1) regulates the balance of root tip cell proliferation and differentiation by controlling the expression of a set of peroxidases and therefore the balance of $\mathrm{O}_{2}{ }^{--}$and $\mathrm{H}_{2} \mathrm{O}_{2}$ (Tsukagoshi et al. 2010). Ectopic expression of UPB1 represses the peroxidases and results in $\mathrm{H}_{2} \mathrm{O}_{2}$ accumulation and decreased meristem size in the root tip (Tsukagoshi et al. 2010). In osacbp6 root, reduction in root meristem activity, repression in gene expression of a set of peroxidases, decrease in peroxidase activities, and accumulation of $\mathrm{H}_{2} \mathrm{O}_{2}$ occurred, which were restored in the complemented lines. These findings are partially consistent with ROS-controlled root growth regulated by UPB1 (Tsukagoshi et al. 2010). Unfortunately, as a UPB1 orthologue has not been identified in the rice genome using a BLAST search in NCBI (National Center for Biotechnology Information, http://blast.ncbi.nlm.nih.gov/Blast.cgi), the TF responsible for such regulation remains elusive.

The regulatory mechanisms for the growth of leaf and root are known to be different (Lu et al. 2014). In Arabidopsis, leaf growth and final size are controlled by MYBlike TF KUODA1 (KUA1)-regulated peroxidase activities which in turn maintain ROS homeostasis (Lu et al. 2014). Although leaf and root growth are controlled by different TFs, the direct targets of these TFs are peroxidases and by regulation in the expression of peroxidases, ROS homeostasis is maintained (Tsukagoshi et al. 2010; Lu et al. 2014). In osacbp6, compromised leaf development was represented by slow elongation and accompanied by a high $\mathrm{H}_{2} \mathrm{O}_{2}$ level. Consistent with root, leaf peroxidases of osacbp 6 were also differentially expressed and activities were reduced. In addition, given that $\mathrm{O}_{2}{ }^{-}$ can be converted to $\mathrm{H}_{2} \mathrm{O}_{2}$ spontaneously or by enzymatic activities (Apel and Hirt 2004), the elevated level of $\mathrm{O}_{2}{ }^{--}$in osacbp6 also might be an alternative source of $\mathrm{H}_{2} \mathrm{O}_{2}$ accumulation. Due to the complexity of peroxidases in promoting or restricting plant growth (Passardi et al. 2004), the regulation mechanism of the reduced peroxidase activities and accumulation of ROS in retarded leaf development of osacbp6 were elusive. They might contribute to abnormal cell proliferation or differentiation and ultimately reduce leaf development. Taken together, from the findings on root and leaf, retarded growth in osacbp6 mostly possible resulted from a disruption of ROS homeostasis. On the other hand, as a higher level of $\mathrm{H}_{2} \mathrm{O}_{2}$ occurred throughout osacbp 6 development, it appears that stress response is constitutively activated in osacbp6. Diminished growth of osacbp6 is consistent with studies on growth-defense tradeoffs, in which plant growth is inhibited by the activation of defense responses (Guo et al. 2018). Meanwhile, the examination of various plant hormones further supports this hypothesis. Alteration in the plant 
hormone levels was noted in osacbp6, especially an increase in JA content. The core jasmonate signaling pathway functions in the perception of various developmental and stress-related cues and mediation of transcriptional responses (Howe et al. 2018). One of the output responses of the jasmonate signaling pathway is developmental responses, including growth inhibition, defensive structures, and effects on reproduction and fertility (Howe et al. 2018). As the first step of JA biosynthesis, plants employ different lipases to liberate $\alpha$-LeA from chloroplast membrane lipids, including DONGLE (DGL), DEFECTIVE IN ANTHER DEHISCENCE1 (DAD1), and phospholipase A (PLA) PLA-IY1 in Arabidopsis, PLD $\alpha 4$ and $\alpha 5$ and EG1 in rice (Ellinger et al. 2010; Qi et al. 2011; Cai et al. 2014). In contrast to an induction triggered in JA biosynthesis (Qi et al. 2011), PLD $\alpha 4$ and $\alpha 5$ showed no change in osacbp6. Despite that EG1 is mainly required for development in rice (Cai et al. 2014), there was no change for EG1 in osacbp6. Limited alteration in expression of these lipases is consistent with lack in an obvious loss of chloroplast membrane lipids in comparison to the wild type, suggesting $\alpha$-LeA in osacbp 6 is sufficient to produce enough JA to confer the balance between growth and defense. Amongst enzymes involved in JA biosynthesis, only DOX and AOS were induced in osacbp6. Given that DOX is activated by $\mathrm{H}_{2} \mathrm{O}_{2}$ ( $\mathrm{Zhu}$ et al. 2013), enhanced of JA biosynthesis in osacbp 6 under normal growth conditions appears to be a perception of the elevated $\mathrm{H}_{2} \mathrm{O}_{2}$ level and in turn adjusted the corresponding transcriptional responses to diminish growth. Elevated JA level in osacbp6 indicated that JA production from the $\beta$-oxidation of JA precursor, OPDA, was not blocked due to the loss of OsACBP6. As we discussed above, OsACBP6 would not be responsible for direct import of substrate into the peroxisomes. Therefore, in combination with the changes in the expression of genes related to JA biosynthesis, elevated JA level is most likely resulted from the secondary effects of the loss of OsACBP6.

Acyl-CoA esters are not only important intermediates in lipid metabolism but also play a role in regulating multiple cellular processes (Schmidt et al. 2018; Lung and Chye 2019). Recently, direct evidence showed that acyl-CoA esters function in the cellular signaling pathway in Arabidopsis (Schmidt et al. 2018). An increased C18:1-CoA level promoted the dissociation of TF RELA TED TO APETALA 2.12 (RAP2.12) with its partner AtACBP1, which determined subsequent hypoxiaspecific gene expression (Schmidt et al. 2018). Meanwhile, C16:0-CoA, C18:0-CoA, and C18:1-CoA triggered distinct transcriptional responses (Schmidt et al. 2018). Our findings that elevated acyl-CoA content in osacbp6 was accompanied by alterations in lipid composition as well as ROS and plant hormone levels further support the critical roles of acyl-CoA esters in the signaling network in both dicots and monocots. Although OsACBP6 has two cytosolic orthologues (AtACBP4 and AtACBP5) in Arabidopsis, a mere single mutation in any made them indistinguishable from the wild type (Hsiao et al. 2015). Even in the acbp $4 a c b p 5$ double mutant, the phenotypic discrepancy was limited because another cytosolic AtACBP6 co-exists (Hsiao et al. 2015). Based on our results, a mutation in OsACBP6 led to phenotypic and physiological changes in rice. Furthermore, the correlation of increased acyl-CoA pool size with the loss of OsACBP6 also suggests a possible role of overexpression of OsACBP6 in the wild type in facilitating acylCoAs utilization.

\section{Conclusions}

In conclusion, acyl-CoA profiling in this study revealed the role of ACBPs in acyl-CoA utilization is conserved in both Arabidopsis and rice. However, it is worth mentioning that growth retardation in osacbp6 was associated with a series of changes including changes in acylCoA pool size, lipid metabolism, ROS content, and plant hormone levels as well as other transcriptional response, indicating the correlation of enhanced acyl-CoAs content with defense responses.

\section{Methods}

\section{Plant Materials and Growth Conditions}

T-DNA line PFG_1B-14,906 (designated as osacbp6) was obtained from Postech PFG T-DNA, South Korea (Ryu et al. 2004). To prepare the samples for transcriptomic analysis, seeds of wild-type rice (Oryza sativa var. japonica cv. Dongjin) and osacbp6 were soaked in water and germinated in dark at $25^{\circ} \mathrm{C}$ for 2 days. To collect the roots and shoots, germinated seeds grown in water were placed in the growth chamber under a 10 -h-light $\left(30^{\circ} \mathrm{C}\right)$ / 14-h-dark $\left(28^{\circ} \mathrm{C}\right)$ cycle. Roots and shoots were sampled separately at 5 and 7 days after imbibition. To collect the leaf blade, germinated seeds were grown in soil under the same growth condition as described above. The leaf blades were collected at 21 days after imbibition. For IBA treatment, germinated seeds were hydroponically cultured in Hoagland solution supplemented with $10 \mathrm{mg} \mathrm{L}^{-1}$ IBA for 7 days. Cell proliferation in the root meristem was visualized by the incorporation of EdU into DNA at S-phase (Kotogany et al. 2010). EdU staining was performed using an EdU kit (C10310, Apollo 488, Ribobio) according to $\mathrm{Li}$ et al. (2015). Briefly, roots of 5 -day-old rice seedlings (10 seedlings for each genotype) were immersed in a $50 \mu \mathrm{M}$ EdU solution for $2 \mathrm{~h}$. After fixation in $4 \%$ paraformaldehyde for 30 min, roots were incubated with freshly-prepared Apollo solution for $30 \mathrm{~min}$, followed by 4',6-Diamidino-2-Phenylindole (DAPI, $1 \mathrm{mg} \mathrm{mL}^{-1}$ ) staining for $10 \mathrm{~min}$ and 
fluorescence microscopy. Images were analyzed using ImageJ software (Schneider et al. 2012). In order to observe leaf elongation, the length of the third leaf was measured daily with a ruler using the top edge of the pot as a reference (Pettko-Szandtner et al. 2015). Measurements were carried out on five plants starting from the emergence of the third leaf for 6 days.

\section{T-DNA Confirmation}

The gene-specific primer (ML2067) and T-DNA left border primer (2717-LB) were used in PCR to confirm the T-DNA insertion in PFG_1B-14,906 (osacbp6). The combinations of gene-specific primer pair ML2066/ ML2067 and 2717-LB/ML2067 were used to screen for the homozygote mutant. Gene-specific primer pair ML1050 and ML1051 was used in semiquantitative RTPCR to detect OsACBP6 expression. The primer sequences were ML2066: 5'-ATCAGGGCTGAGGTGC TA-3'; ML2067: 5'-AGGGCTTCAGAATCGTATGG3'; 2717-LB: 5' -ACGCTGAACTTGTGGCCGTT-3'; ML1050: 5' -CCAGATCTTCCCGCTTCCAGAACGAC3'; and ML1051: 5' -CTGAATTCTTAAGTCATGCCCT CACTG-3'.

\section{Generation of osacbp6-Complemented Transgenic Rice}

An OsACBP6 putative promoter region containing 2.0$\mathrm{kb}$ upstream of the transcription start site was amplified using PCR with primer pair Promoter-F (5'CAGTCGTCTCACAACTGCCACTGTAAATTTGT

CTA-3' with the BsmBI underlined) and Promoter-R (5' -CAGTCGTCTCAGCTTCGCGGGCGATGAATGA3' with BsmBI underlined). The 1.97-kb open reading frame (ORF) of OsACBP6 was amplified by RT-PCR using primer pair ORF-F (5' -CAGTCGTCTCAAAGCA TGGCGAGCTCCGGACTCGC-3' with BsmBI underlined) and ORF-R (5'-CAGTCGTCTCATACATCAAG ACTCGGACTTATCAG-3' with BsmBI underlined). To construct the OsACBP6 promoter driving OsACBP6 cDNA plasmid ( $p O s A C B P 6:: O s A C B P 6)$ for complementation, the PCR products of promoter and ORF were digested by $B s m \mathrm{BI}$, and the binary vector $\mathrm{pBWA}(\mathrm{V}) \mathrm{H}$ ccdb-Tnos was digested by Eco31I. The promoter and the ORF regions were ligated to the vector $\mathrm{pBWA}(\mathrm{V}) \mathrm{H}$ ccdb-Tnos using T4 ligase. The $p O s A C B P 6:: O s A C B P 6$ construct was then introduced into osacbp 6 by Agrobacterium-mediated transformation. Positive transgenic rice lines were confirmed by PCR and hygromycin screening, and the T3 generation was used to observe changes in the phenotype.

\section{Acyl-CoA and Lipid Profiling}

For acyl-CoA measurement, acyl-CoA esters were extracted from freshly harvested leaves from at least five individual 21-day-old (100 mg, three replicates) soil- grown plants according to Woldegiorgis et al. (1985) and Larson and Graham (2001). For lipid profiling, leaves from at least five individual 21-day-old soil-grown plants were freshly collected for analysis $(60 \mathrm{mg}$, three replicates). Plant materials were inactivated with hot isopropanol, and total lipid extraction was performed as previously described (Welti et al. 2002).

Lipid and acyl-CoA measurements were performed on Exion UPLC coupled with QTRAP 6500 PLUS (SCIEX) under the conditions: curtain gas $=20 \mathrm{psi}$, ion spray voltage $=5500 \mathrm{~V}$, temperature $=400^{\circ} \mathrm{C}$, ion source gas $1=$ $35 \mathrm{psi}$, and ion source gas $2=35$ psi. Polar lipid and glycerol lipids (diacylglycerols (DAGs) and TAGs) were analyzed as previously described (Lam et al. 2014; Gao et al. 2017). Separation of galactolipids MGDG and DGDG were achieved according to Cheong et al. (2014) and Gao et al. (2017).

\section{Transcriptomic Analysis and DEG Identification}

Total RNA from 5-day-old roots, 5-day-old shoots, 7day-old roots, 7-day-old shoots and 21-day-old leaves, respectively, was extracted using the RNeasy Plant Mini Kit (Qiagen). Transcriptome analysis was conducted at Annoroad Gene Technology Corporation (Beijing, China). The data from three replicates were collected and analyzed. Genes whose expression is increased by over $100 \%$ or decreased by over $50 \%$ with adjusted $P$ value $\leq 0.05$ were considered as DEGs.

\section{Gene Ontology Enrichment and MapMan Analysis}

GO enrichment was performed using AgriGO v2.0 (Tian et al. 2017) (http://systemsbiology.cau.edu.cn/agriGOv2/ ). Under the species "Oryza sativa japonica", singular enrichment analysis was performed. GO terms in biological process with FDR value $<0.005$ were considered as significant and analyzed further. The biological processes and metabolic pathways were systematically evaluated using MapMan analysis (Thimm et al. 2004), MapMan software version 3.6.0RC1 (https://mapman. gabipd.org/) was employed. The rice gene identifier (osa_MSU_v7_2017-09-05_mapping.txt) that was imported to MapMan was downloaded from GoMapMan (Ramsak et al. 2014) (http://www.gomapman.org/ export/current/mapman). The "Metabolism overview" and the "Cellular response" sections of MapMan were used to display the changes in DEGs with putative functions.

\section{Quantitative Real-Time RT-PCR}

Total RNA from 7-day-old roots, 7-day-old shoots and 21-day-old leaves, respectively, was extracted using the RNeasy Plant Mini Kit (Qiagen) and reverse transcribed by ReverTra Ace ${ }^{\circ}$ qPCR RT Master Mix with gDNA Remover (Toyobo). qRT-PCR was performed on Light- 
Cycler Roche 480 (Roche) with LightCycler 480 SYBR Green I Master (Roche) under the following conditions: $95^{\circ} \mathrm{C}$ for $10 \mathrm{~min}$, then 40 cycles of $95^{\circ} \mathrm{C}$ for $10 \mathrm{~s}$ and $60{ }^{\circ} \mathrm{C}$ for $20 \mathrm{~s}$. Primer sequences were listed in Dataset S10. ACTIN1 and UBIQUITIN1 were used as reference genes. The relative expression level was calculated using the $2^{-\Delta \Delta \mathrm{Ct}}$ method (Schmittgen and Livak 2008).

\section{Detection of ROS and Quantitative Measurement of Hydrogen Peroxide $\left(\mathrm{H}_{2} \mathrm{O}_{2}\right)$}

Nitroblue tetrazolium (NBT) and 3,3'-diaminobenzidine tetrahydrochloride (DAB) staining were conducted as described by Fukao et al. (2011). Each leaf blade from a 21-day-old rice plant grown in soil was immersed in a solution containing $0.5 \mathrm{mg} \mathrm{mL}^{-1} \mathrm{NBT}$ (dissolved in 10 $\mathrm{mM}$ potassium phosphate buffer, $\mathrm{pH} 7.6)$ and $1 \mathrm{mg}$ $\mathrm{mL}^{-1}$ DAB (dissolved in $50 \mathrm{mM}$ Tris-Acetate buffer, $\mathrm{pH}$ 5.0). After incubation under vacuum for $5 \mathrm{~min}$, samples were kept in the dark at $25^{\circ} \mathrm{C}$ for $3 \mathrm{~h}$ for NBT staining and $24 \mathrm{~h}$ for DAB staining. Subsequently, plant materials were boiled in $95 \%(\mathrm{v} / \mathrm{v})$ ethanol for $20 \mathrm{~min}$ to remove chlorophyll and rehydrated in 40\% (v/v) glycerol. Each experiment was repeated on at least five plants and representative images are displayed.

$\mathrm{H}_{2} \mathrm{O}_{2}$ content was measured using the Amplex Red Hydrogen Peroxide/Peroxidase Assay Kit (Invitrogen). Briefly, roots and shoots of 7-day-old seedlings and 21day-old leaf blades from at least three individual plants were freshly collected (50 mg, three replicates) and ground to a fine powder in liquid nitrogen followed by the immediate addition of $1 \mathrm{~mL}$ ice-cold $20 \mathrm{mM}$ sodium phosphate buffer ( $\mathrm{pH} 6.5$ ). The supernatant was collected by centrifugation $\left(10,000 \mathrm{~g}, 4^{\circ} \mathrm{C}, 10 \mathrm{~min}\right)$ followed by analysis according to the manufacturer's instructions.

\section{Measurement of Antioxidative Enzyme Activity}

Peroxidase activity was measured according to Chen et al. (2013). Briefly, roots and shoots of 7-day-old seedlings and 21-day-old leaf blades from at least six individual plants were freshly collected and ground in $50 \mathrm{mM}$ sodium phosphate buffer ( $\mathrm{pH}$ 7.8) supplemented with $1 \%$ polyvinylpyrrolidone and $\beta$-mercaptoethanol $(1: 5, \mathrm{~m} /$ v) on ice. The supernatant was collected after centrifugation $\left(13,000 \mathrm{~g}, 4{ }^{\circ} \mathrm{C}, 15 \mathrm{~min}\right)$ and used for peroxidase activity assay. The reaction mixture $(2 \mathrm{~mL})$ composed of $50 \mathrm{mM}$ sodium acetate buffer (pH 5.6), $5.4 \mathrm{mM}$ guaiacol, $15 \mathrm{mM} \mathrm{H}_{2} \mathrm{O}_{2}$, and $100 \mu \mathrm{L}$ of enzyme extract. The absorbance at $470 \mathrm{~nm}$ increase in $1 \mathrm{~min}$ was recorded using Cary 60 UV-Vis (Agilent). Peroxidase activity was determined by the increase in the absorbance at $470 \mathrm{~nm}$ per minute per $\mathrm{mg}$ protein. The enzyme extract from 21day-old leaf blades was also used for determination of CAT, APX and MDAR activity. CAT and APX activity were measured according to $\mathrm{Wu}$ and Yang (2016). The reaction mixture for CAT activity determination composed of composed of $50 \mathrm{mM}$ sodium phosphate buffer (pH 7.8) $1.5 \mathrm{~mL}, \mathrm{ddH}_{2} \mathrm{O} 1 \mathrm{~mL}$, enzyme extract $200 \mu \mathrm{L}$ and $300 \mu \mathrm{L} 0.1 \mathrm{M} \mathrm{H}_{2} \mathrm{O}_{2}$. The reaction mixture for APX activity determination composed of $50 \mathrm{mM}$ sodium phosphate buffer (pH 7.8) $1.25 \mathrm{~mL}, 5 \mathrm{mM}$ ascorbic acid (AsA) $200 \mu \mathrm{L}$, enzyme extract $50 \mu \mathrm{L}$ and $500 \mu \mathrm{L} 0.1 \mathrm{mM}$ $\mathrm{H}_{2} \mathrm{O}_{2}$. While MDAR activity was measured according to Hossain and Asada (1985). The reaction mixture composed of $50 \mathrm{mM}$ sodium phosphate buffer ( $\mathrm{pH} 7.8$ ) $450 \mu \mathrm{L}, 0.1 \mathrm{mM}$ AsA $500 \mu \mathrm{L}, 0.1 \mathrm{mM}$ NADH $800 \mu \mathrm{L}$, enzyme extract $100 \mu \mathrm{L}$ and 0.14 unit of ascorbate oxidase. CAT, APX and MDAR activity were determined by the decrease in the absorbance at $240 \mathrm{~nm}, 290 \mathrm{~nm}$ and 340 $\mathrm{nm}$, respectively, per minute per mg protein.

\section{Quantification of Plant Hormones}

Plant hormone extraction and quantification were conducted according to Pan et al. (2010) with minor modifications. Briefly, leaf tissue was ground into fine powder in liquid nitrogen. Plant hormones were extracted from $1 \mathrm{~g}$ powder with $10 \mathrm{~mL}$ isopropanol $/ \mathrm{H}_{2} \mathrm{O} /$ concentrated $\mathrm{HCl}(2: 1: 0.002, \mathrm{v} / \mathrm{v} / \mathrm{v})$ extraction buffer supplemented with $8 \mu \mathrm{L}$ internal standards solution containing $1 \mu \mathrm{g}$ $\mathrm{mL}^{-1}$ of each internal standard compound $\left(\mathrm{d}_{5}-\mathrm{IAA}, \mathrm{d}_{6}\right.$ ABA, $d_{6}-S A, H_{2} J A$, and $d_{2}-G_{4}$ ). After shaking for 30 min at $4{ }^{\circ} \mathrm{C}, 20 \mathrm{~mL}$ dichloromethane was added to the extraction buffer followed by further shaking for $30 \mathrm{~min}$ at $4{ }^{\circ} \mathrm{C}$. Samples were then centrifuged at $13000 \mathrm{~g}$ for 5 min and the lower phase was transferred, concentrated to dryness with nitrogen flow in the dark and resolved with $400 \mu \mathrm{L}$ methanol ( $0.1 \%$ formic acid). Hormones were quantified using HPLC-MS/MS (SCIEX 6500 QTRAP) equipped with Poroshell 120 SB-C18 column (Agilent).

\section{Supplementary Information}

The online version contains supplementary material available at https://doi. org/10.1186/s12284-020-00435-y.

Additional file 1: Fig. S1 Growth of the rice osacbp6 mutant and the wild type (WT) in soil. a Images representing 5- and 7-day-old seedlings grown in soil. Bars, $1 \mathrm{~cm}$. b Shoot and primary root length comparison between WT and osacbp6 (left) and primary root reduction of osacbp6 (right) Values are means \pm SD $(n=13)$. Asterisks indicate significant differences between WT and osacbp6 as evaluated by Student's t-tests: ${ }^{* * *} P<$ 0.001 . WT, Oryza sativa var. japonica cv. Dongjin.

Additional file 2: Fig. S2 Grain size and indole-3-butyric acid (IBA) sensitivity of osacbp6. a The grain length of osacbp6 is shorter than WT. Values are means \pm SD $(n=30)$. Asterisks indicate significant differences between WT and osacbp6 as evaluated by Student's t-tests: ${ }^{* *} P<0.001$ b osacbp6 is sensitive to the growth inhibition effect of IBA. Values are means \pm SD $(n=5)$. Asterisks indicate significant differences between mock and IBA treatment as evaluated by Student's $t$-tests: ${ }^{* *} P<0.001$. WT, Oryza sativa var. japonica cv. Dongjin.

Additional file 3: Fig. S3 Recovery in leaf and grain length of the rice osacbp6 mutant by complementation of OSACBP6. a Relative expression 
of OSACBP6 in the 7-day-old seedlings from the wild type (WT), osacbp6, complemented lines osacbp6-C1 (C1), osacbp6-C2 (C2) and osacbp6-C4 (C4) measured by quantitative real time RT-PCR (qRT-PCR) using OsACBP6 specific primer pair ML1113 and ML1114. Values are means \pm SD $(n=3)$. $\mathbf{b}$ and $\mathbf{c}$ Leaf length of 21-day-old soil-grown seedlings (b) and grain size (c) are compared amongst osacbp6, WT, and the complemented lines $\mathrm{C1}$, $C 2$ and C4. Values are mean \pm SD (leaf length: $n=5$; grain size: $n=30$ ). L, value of osacbp6 lower than WT and the complemented lines. $\mathrm{H}$, value of the complemented line higher than WT. Asterisks indicate significant differences as evaluated by Student's $t$-tests: ${ }^{*} P<0.05,{ }^{* *} P<0.01,{ }^{* * *} P<$ 0.001. WT, Oryza sativa var. japonica cv. Dongjin.

Additional file 4: Fig. S4 Expression of OSACBP6 from the Rice eFP Browser. Absolute expression levels in the seedling root, young leaf and mature leaf were retrieved from the Rice eFP Browser (http://bar. utoronto.ca/efprice/cgi-bin/efpWeb.cgi).

Additional file 5: Fig. S5 Membrane lipid content ( $\mathrm{mol} \%$ of total) in 21-day-old leaves. Values are means \pm SD $(n=3)$. WT, wild type; $C 4$, complemented line osacbp6-C4; PC, Phosphatidylcholine; PE, Phosphatidylethanolamine; PI, Phosphatidylinositol; PS, Phosphatidylserine; PA Phosphatidic acid; MGDG, Monogalactosyldiacylglycerol; DGDG, Digalactosyldiacylglycerol; PG, Phosphatidylglycerol.

Additional file 6: Fig. S6 Differential expression of genes involved in lipid metabolism in osacbp6. a-c Expression of genes associated with fatty acid synthesis and elongation (a) phospholipid synthesis (b), and lipid degradation (c), respectively. Values are mean of $\log _{2}$ fold change $(n=3)$. The color in each cell represents the expression level based on the $\log _{2}$ fold change. Cells without color indicate the genes were not differentially expressed. R5, 5-day-old roots; R7, 7-day-old roots; S5, 5-dayold shoots; S7, 7-day-old shoots; L21, 21-day-old leaves. KCS, betaketoacyl-CoA synthase; ACSL, long-chain acyl-CoA synthetase; FAD, omega-3 fatty acid desaturase; GPAT, glycerol 3-phosphate acyltransferase; CFA, cyclopropane-fatty-acyl-phospholipid synthase; GDSL, GDSL-like lipase; SDR, short-chain dehydrogenases/reductase.

Additional file 7: Fig. S7 Analysis of differentially expressed genes related to cellular response and regulation in osacbp6. a Numbers of differentially expressed genes at different stages and organs. $\mathbf{b}$ and $\mathbf{c}$ Heat map of phytohormones (b) and selected transcription factors (c) in osacbp6 based on the MapMan results, respectively. Each square represents a differentially expressed gene. The color indicates the level of up-regulation (red) and down-regulation (blue) based on the value of mean $\log _{2}$ fold change $(n=3)$. The full list of differentially expressed genes is displayed in Dataset S8 and S9. BR, brassinosteroid; GA, gibberellin; ABA, abscisic acid; JA, jasmonic acid; SA, salicylic acid; AP2/EREBP, APETALA2/ethylene-responsive element binding protein family; bZIP, basic leucine zipper transcription factor family; MYB, myeloblastosis transcription factor family; WRKY, WRKY transcription factor family; ABI3NP1, ABA-INSENSITIVE3/VIVIPAROUSI transcription factor family; bHLH, basic helix-loop-helix transcription factor family; Aux/IAA, auxin/indole-3-acetic acid transcription factor family: NAC, NO APICAL MERISTEM (NAM), ARABIDOPSIS TRANSCRIPTION ACTIVATION FACTOR1-2 (ATAF1/2), and CUPSHAPED COTYLEDON2 (CUC2) transcription factor family.

Additional file 8: Fig. $\mathbf{S 8}$ Expression of peroxidases from the Rice efP Browser. Absolute expression levels in the seedling root, young leaf, and mature leaf were retrieved from the Rice eFP Browser (http://bar. utoronto.ca/efprice/cgi-bin/efpWeb.cgi).

Additional file 9. Dataset $\mathrm{S} 1-\mathrm{S} 10$

\section{Acknowledgments}

We thank Qingzhu Zhang (Northeast Forestry University) on comments on the transcriptome data.

\section{Authors' Contributions}

M.L.C. and W.M. conceived the research plan; W.M., L.X., F.W., R.Z. and X.S. performed the experiments; G.S. and S.M.L. conducted lipid and acyl-CoA profiling; W.M., Z.Y.D., Y.L. and M.L.C. analyzed the data and wrote the article. All authors have read and approved the final manuscript.

\section{Funding}

This work is supported by the grants from Fundamental Research Funds for the Central Universities (2572017CA20), Natural Science Foundation of Heilongjiang Province of China (QC2015033), National Natural Science Foundation of China (31500202 and 31870528), China Postdoctoral Science Foundation (2015 M571380), and the Research Grants Council of Hong Kong (HKU17105615M)

\section{Availability of Data and Materials}

The datasets supporting the conclusions of this article are included within the article and its additional files.

\section{Ethics Approval and Consent to Participate}

Not applicable.

\section{Consent for Publication}

All authors are consent for publication.

\section{Competing Interests}

The authors declare that they have no competing interests.

\section{Author details}

${ }^{1}$ Key Laboratory of Saline-alkali Vegetation Ecology Restoration (Northeast Forestry University), Ministry of Education, Harbin 150040, China. ${ }^{2}$ College of Life Science, Northeast Forestry University, Harbin 150040, China. ${ }^{3}$ College of Advanced Agriculture and Ecological Environment, Heilongjiang University, Harbin 150080, China. ${ }^{4}$ Department of Biosciences and Bioengineering, University of Hawaii at Manoa, Honolulu, HI 96822, USA. ${ }^{5}$ School of Biological Sciences, The University of Hong Kong, Pokfulam, Hong Kong. 'State Key Laboratory of Molecular Developmental Biology, Institute of Genetics and Developmental Biology, Chinese Academy of Sciences, Beijing, China. ${ }^{7}$ Lipidall Technologies Company Limited, Changzhou 213000, China.

Received: 13 July 2020 Accepted: 21 October 2020

Published online: 06 November 2020

\section{References}

Amiruddin N, Chan PL, Azizi N, Morris PE, Chan KL, Ong PW, Rosli R, Masura SS, Murphy DJ, Sambanthamurthi R, Haslam RP, Chye ML, Harwood JL, Low EL (2020) Characterization of oil palm acyl-CoA-binding proteins and correlation of their gene expression with oil synthesis. Plant Cell Physiol 61:735-747

Apel K, Hirt H (2004) Reactive oxygen species: metabolism, oxidative stress, and signal transduction. Annu Rev Plant Biol 55:373-399

Cai Q, Yuan Z, Chen M, Yin C, Luo Z, Zhao X, Liang W, Hu J, Zhang D (2014) Jasmonic acid regulates spikelet development in rice. Nat Commun 5:3476

Chen LJ, Wuriyanghan H, Zhang YQ, Duan KX, Chen HW, Li QT, Lu X, He SJ, Ma B, Zhang WK, Lin Q, Chen SY, Zhang JS (2013) An S-domain receptor-like kinase, OsSIK2, confers abiotic stress tolerance and delays dark-induced leaf senescence in rice. Plant Physiol 163:1752-1765

Chen QF, Xiao S, Chye ML (2008) Overexpression of the Arabidopsis 10-kilodalton acyl-coenzyme A-binding protein ACBP6 enhances freezing tolerance. Plant Physiol 148:304-315

Chen QF, Xiao S, Qi W, Mishra G, Ma J, Wang M, Chye ML (2010) The Arabidopsis acbp1acbp2 double mutant lacking acyl-CoA-binding proteins ACBP1 and ACBP2 is embryo lethal. New Phytol 186:843-855

Cheong WF, Wenk MR, Shui G (2014) Comprehensive analysis of lipid composition in crude palm oil using multiple lipidomic approaches. J Genet Genomics 41:293-304

De Marcos LC, van Roermund CW, Postis VL, Dietrich D, Kerr ID, Wanders RJ, Baldwin SA, Baker A, Theodoulou FL (2013) Intrinsic acyl-CoA thioesterase activity of a peroxisomal ATP binding cassette transporter is required for transport and metabolism of fatty acids. Proc Natl Acad Sci U S A 110:12791284

Du ZY, Arias T, Meng W, Chye ML (2016) Plant acyl-CoA-binding proteins: An emerging family involved in plant development and stress responses. Prog Lipid Res 63:165-181

Du ZY, Chen MX, Chen QF, Xiao S, Chye ML (2013) Arabidopsis acyl-CoA-binding protein ACBP1 participates in the regulation of seed germination and seedling development. Plant J 74:294-309 
Du ZY, Xiao S, Chen QF, Chye ML (2010) Depletion of the membrane-associated acyl-coenzyme A-binding protein ACBP1 enhances the ability of cold acclimation in Arabidopsis. Plant Physiol 152:1585-1597

Eastmond PJ (2007) MONODEHYROASCORBATE REDUCTASE4 is required for seed storage oil hydrolysis and postgerminative growth in Arabidopsis. Plant Cell 19:1376-1387

Ellinger D, Stingl N, Kubigsteltig II, Bals T, Juenger M, Pollmann S, Berger S, Schuenemann D, Mueller MJ (2010) DONGLE and DEFECTIVE IN ANTHER DEHISCENCE1 lipases are not essential for wound- and pathogen-induced jasmonate biosynthesis: redundant lipases contribute to jasmonate formation. Plant Physiol 153:114-127

Fukao T, Yeung E, Bailey-Serres J (2011) The submergence tolerance regulator SUB1A mediates crosstalk between submergence and drought tolerance in rice. Plant Cell 23:412-427

Fulda M, Schnurr J, Abbadi A, Heinz E, Browse J (2004) Peroxisomal acyl-CoA synthetase activity is essential for seedling development in Arabidopsis thaliana. Plant Cell 16:394-405

Gao M, Yin X, Yang W, Lam SM, Tong X, Liu J, Wang X, Li Q, Shui G, He Z (2017) GDSL lipases modulate immunity through lipid homeostasis in rice. PLoS Pathog 13:e1006724

Germain V, Rylott EL, Larson TR, Sherson SM, Bechtold N, Carde JP, Bryce JH, Graham IA, Smith SM (2001) Requirement for 3-ketoacyl-CoA thiolase-2 in peroxisome development, fatty acid beta-oxidation and breakdown of triacylglycerol in lipid bodies of Arabidopsis seedlings. Plant J 28:1-12

Graham IA (2008) Seed storage oil mobilization. Annu Rev Plant Biol 59:115-142

Guo HM, Li HC, Zhou SR, Xue HW, Miao XX (2014) Cis-12-oxo-phytodienoic acid stimulates rice defense response to a piercing-sucking insect. Mol Plant 7:1683-1692

Guo Q, Major IT, Howe GA (2018) Resolution of growth-defense conflict: mechanistic insights from jasmonate signaling. Curr Opin Plant Biol 44:72-81

Guo ZH, Chan WHY, Kong GKW, Hao Q, Chye ML (2017) The first plant acyl-CoAbinding protein structures: the close homologues OsACBP1 and OsACBP2 from rice. Acta Crystallogr D Struct Biol 73:438-448

Hossain MA, Asada K (1985) Monodehydroascorbate reductase from cucumber is a flavin adenine dinucleotide enzyme. J Biol Chem 260:12920-12926

Howe GA, Major IT, Koo AJ (2018) Modularity in Jasmonate signaling for multistress resilience. Annu Rev Plant Biol 69:387-415

Hsiao AS, Haslam RP, Michaelson LV, Liao P, Chen QF, Sooriyaarachchi S, Mowbray SL, Napier JA, Tanner JA, Chye ML (2014a) Arabidopsis cytosolic acyl-CoA-binding proteins ACBP4, ACBP5 and ACBP6 have overlapping but distinct roles in seed development. Biosci Rep 34:e00165

Hsiao AS, Yeung EC, Ye ZW, Chye ML (2015) The Arabidopsis cytosolic acyl-CoA binding proteins play combinatory roles in pollen development. Plant Cell Physiol 56:322-333

Hu J, Baker A, Bartel B, Linka N, Mullen RT, Reumann S, Zolman BK (2012) Plant peroxisomes: biogenesis and function. Plant Cell 24:2279-2303

Kaur N, Hu J (2011) Defining the plant peroxisomal proteome: from Arabidopsis to rice. Front Plant Sci 2:103

Kelly AA, van Erp H, Quettier AL, Shaw E, Menard G, Kurup S, Eastmond PJ (2013) The sugar-dependent1 lipase limits triacylglycerol accumulation in vegetative tissues of Arabidopsis. Plant Physiol 162:1282-1289

Knudsen J, Neergaard TB, Gaigg B, Jensen MV, Hansen JK (2000) Role of acyl-CoA binding protein in acyl-CoA metabolism and acyl-CoA-mediated cell signaling. J Nutr 130:294S-298S

Koeduka T, Matsui K, Hasegawa M, Akakabe Y, Kajiwara T (2005) Rice fatty acid -dioxygenase is induced by pathogen attack and heavy metal stress: activation through jasmonate signaling. J Plant Physiol 162:912-920

Kotogany E, Dudits D, Horvath GV, Ayaydin F (2010) A rapid and robust assay for detection of S-phase cell cycle progression in plant cells and tissues by using ethynyl deoxyuridine. Plant Methods 6:5

Lam SM, Tong L, Duan X, Petznick A, Wenk MR, Shui G (2014) Extensive characterization of human tear fluid collected using different techniques unravels the presence of novel lipid amphiphiles. J Lipid Res 55:289-298

Larson TR, Graham IA (2001) Technical advance: a novel technique for the sensitive quantification of acyl CoA esters from plant tissues. Plant J 25: $115-125$

Li J, Zhao Y, Chu H, Wang L, Fu Y, Liu P, Upadhyaya N, Chen C, Mou T, Feng Y, Kumar P, Xu J (2015) SHOEBOX modulates root meristem size in Rice through dose-dependent effects of gibberellins on cell elongation and proliferation. PLoS Genet 11:e1005464

Liao P, Woodfield HK, Harwood JL, Chye ML, Scofield S (2019) Comparative transcriptomics analysis of Brassica napus $L$. during seed maturation reveals dynamic changes in gene expression between embryos and seed coats and distinct expression profiles of acyl-CoA-binding proteins for lipid accumulation. Plant Cell Physiol 60:2812-2825

Li-Beisson Y, Shorrosh B, Beisson F, Andersson MX, Arondel V, Bates PD, Baud S, Bird D, Debono A, Durrett TP, Franke RB, Graham IA, Katayama K, Kelly AA, Larson T, Markham JE, Miquel M, Molina I, Nishida I, Rowland O, Samuels L, Schmid KM, Wada H, Welti R, Xu C, Zallot R, Ohlrogge J (2013) Acyl-lipid metabolism. Arabidopsis Book 11:e0161

Lu D, Wang T, Persson S, Mueller-Roeber B, Schippers JH (2014) Transcriptional control of ROS homeostasis by KUODA1 regulates cell expansion during leaf development. Nat Commun 5:3767

Lung SC, Chye ML (2016a) The binding versatility of plant acyl-CoA-binding proteins and their significance in lipid metabolism. Biochim Biophys Acta 1861:1409-1421

Lung SC, Chye ML (2016b) Deciphering the roles of acyl-CoA-binding proteins in plant cells. Protoplasma 253:1177-1195

Lung SC, Chye ML (2019) Arabidopsis acyl-CoA-binding proteins regulate the synthesis of lipid signals. New Phytol 223:113-117

Lung SC, Liao P, Yeung EC, Hsiao AS, Xue Y, Chye ML (2018) Arabidopsis ACYLCOA-BINDING PROTEIN1 interacts with STEROL C4-METHYL OXIDASE1-2 to modulate gene expression of homeodomain-leucine zipper IV transcription factors. New Phytol 218:183-200

Mei C, Qi M, Sheng G, Yang Y (2006) Inducible overexpression of a rice allene oxide synthase gene increases the endogenous jasmonic acid level, PR gene expression, and host resistance to fungal infection. MPMI 19:1127-1137

Mendiondo GM, Medhurst A, van Roermund CW, Zhang X, Devonshire J, Scholefield D, Fernandez J, Axcell B, Ramsay L, Waterham HR, Waugh R, Theodoulou FL, Holdsworth MJ (2014) Barley has two peroxisomal ABC transporters with multiple functions in beta-oxidation. J Exp Bot 65:48334847

Meng W, Hsiao AS, Gao C, Jiang L, Chye ML (2014) Subcellular localization of rice acyl-CoA-binding proteins (ACBPs) indicates that OsACBP6:: GFP is targeted to the peroxisomes. New Phytol 203:469-482

Meng W, Su YC, Saunders RM, Chye ML (2011) The rice acyl-CoA-binding protein gene family: phylogeny, expression and functional analysis. New Phytol 189: $1170-1184$

Neess D, Bek S, Engelsby H, Gallego SF, Faergeman NJ (2015) Long-chain acylCoA esters in metabolism and signaling: role of acyl-CoA binding proteins. Prog Lipid Res 59:1-25

Pan X, Welti R, Wang X (2010) Quantitative analysis of major plant hormones in crude plant extracts by high-performance liquid chromatography-mass spectrometry. Nat Protoc 5:986-992

Panthapulakkal Narayanan S, Liao P, Taylor PWJ, Lo C, Chye ML (2019) Overexpression of a monocot acyl-CoA-binding protein confers broadSpectrum pathogen protection in a dicot. Proteomics 19:e1800368

Passardi F, Penel C, Dunand C (2004) Performing the paradoxical: how plant peroxidases modify the cell wall. Trends Plant Sci 9:534-540

Pettko-Szandtner A, Cserhati M, Barroco RM, Hariharan S, Dudits D, Beemster GT (2015) Core cell cycle regulatory genes in rice and their expression profiles across the growth zone of the leaf. J Plant Res 128:953-974

Qi J, Zhou G, Yang L, Erb M, Lu Y, Sun X, Cheng J, Lou Y (2011) The chloroplastlocalized phospholipases $D$ alpha4 and alpha5 regulate herbivore-induced direct and indirect defenses in rice. Plant Physiol 157:1987-1999

Quettier AL, Eastmond PJ (2009) Storage oil hydrolysis during early seedling growth. Plant Physiol Biochem 47:485-490

Raboanatahiry N, Wang B, Yu L, Li M (2018) Functional and structural diversity of acyl-coA binding proteins in oil crops. Front Genet 9:182

Ramsak Z, Baebler S, Rotter A, Korbar M, Mozetic I, Usadel B, Gruden K (2014) GoMapMan: integration, consolidation and visualization of plant gene annotations within the MapMan ontology. Nucleic Acids Res 42:D1167D1175

Richmond TA, Bleecker AB (1999) A defect in beta-oxidation causes abnormal inflorescence development in Arabidopsis. Plant Cell 11:1911-1924

Rylott EL, Eastmond PJ, Gilday AD, Slocombe SP, Larson TR, Baker A, Graham IA (2006) The Arabidopsis thaliana multifunctional protein gene (MFP2) of peroxisomal beta-oxidation is essential for seedling establishment. Plant J 45: 930-941

Ryu C-H, You J-H, Kang H-G, Hur J, Kim Y-H, Han M-J, An K, Chung B-C, Lee C-H, An G (2004) Generation of T-DNA tagging lines with a bidirectional gene trap vector and the establishment of an insertion-site database. Plant Mol Biol 54:489-502 
Schmidt RR, Fulda M, Paul MV, Anders M, Plum F, Weits DA, Kosmacz M, Larson TR, Graham IA, Beemster GTS, Licausi F, Geigenberger P, Schippers JH, van Dongen JT (2018) Low-oxygen response is triggered by an ATP-dependent shift in oleoyl-CoA in Arabidopsis. Proc Natl Acad Sci U S A 115:E12101E12110

Schmittgen TD, Livak KJ (2008) Analyzing real-time PCR data by the comparative C(T) method. Nat Protoc 3:1101-1108

Schneider CA, Rasband WS, Eliceiri KW (2012) NIH image to ImageJ: 25 years of image analysis. Nat Methods 9:671-675

Takato H, Shimidzu M, Ashizawa Y, Takei H, Suzuki S (2013) An acyl-CoA-binding protein from grape that is induced through ER stress confers morphological changes and disease resistance in Arabidopsis. J Plant Physiol 170:591-600

Thimm O, Blasing O, Gibon Y, Nagel A, Meyer S, Kruger P, Selbig J, Muller LA, Rhee SY, Stitt M (2004) MAPMAN: a user-driven tool to display genomics data sets onto diagrams of metabolic pathways and other biological processes. Plant J 37:914-939

Tian T, Liu Y, Yan H, You Q, Yi X, Du Z, Xu W, Su Z (2017) agriGO v2.0: a GO analysis toolkit for the agricultural community, 2017 update. Nucleic Acids Res 45:W122-W129

Tsukagoshi H, Busch W, Benfey PN (2010) Transcriptional regulation of ROS controls transition from proliferation to differentiation in the root. Cell 143: 606-616

Uji Y, Taniguchi S, Tamaoki D, Shishido H, Akimitsu K, Gomi K (2016) Overexpression of OsMYC2 results in the up-regulation of early JArresponsive genes and bacterial blight resistance in rice. Plant Cell Physiol 57: 1814-1827

Wasternack C, Feussner I (2018) The Oxylipin pathways: biochemistry and function. Annu Rev Plant Biol 69:363-386

Welti R, Li W, Li M, Sang Y, Biesiada H, Zhou HE, Rajashekar CB, Williams TD, Wang X (2002) Profiling membrane lipids in plant stress responses. Role of phospholipase $\mathrm{D}$ alpha in freezing-induced lipid changes in Arabidopsis. J Biol 277:31994-32002

Wiszniewski AA, Bussell JD, Long RL, Smith SM (2014) Knockout of the two evolutionarily conserved peroxisomal 3-ketoacyl-CoA thiolases in Arabidopsis recapitulates the abnormal inflorescence meristem 1 phenotype. J Exp Bot 65:6723-6733

Woldegiorgis G, Spennetta T, Corkey BE, Williamson JR, Shrago E (1985) Extraction of tissue long-chain acyl-CoA esters and measurement by reversephase high-performance liquid chromatography. Anal Biochem 150:8-12

Wu YS, Yang CY (2016) Physiological responses and expression profile of NADPH oxidase in rice (Oryza Sativa) seedlings under different levels of submergence. Rice (N Y) 9:2

Xiao S, Gao W, Chen QF, Chan SW, Zheng SX, Ma J, Wang M, Welti R, Chye ML (2010) Overexpression of Arabidopsis acyl-CoA binding protein ACBP3 promotes starvation-induced and age-dependent leaf senescence. Plant Cell 22:1463-1482

Xu L, Zhao H, Ruan W, Deng M, Wang F, Peng J, Luo J, Chen Z, Yi K (2017) ABNORMAL INFLORESCENCE MERISTEM1 functions in salicylic acid biosynthesis to maintain proper reactive oxygen species levels for root MERI STEM activity in Rice. Plant Cell 29:560-574

Zhu G, Koszelak-Rosenblum M, Malkowski MG (2013) Crystal structures of alphadioxygenase from Oryza sativa: insights into substrate binding and activation by hydrogen peroxide. Protein Sci 22:1432-1438

Zolman BK, Silva ID, Bartel B (2001) The Arabidopsis pxa1 mutant is defective in an ATP-binding cassette transporter-like protein required for peroxisomal fatty acid beta-oxidation. Plant Physiol 127:1266-1278

\section{Publisher's Note}

Springer Nature remains neutral with regard to jurisdictional claims in published maps and institutional affiliations.

\section{Submit your manuscript to a SpringerOpen ${ }^{\circ}$ journal and benefit from:}

- Convenient online submission

- Rigorous peer review

- Open access: articles freely available online

- High visibility within the field

- Retaining the copyright to your article

Submit your next manuscript at $\boldsymbol{\nabla}$ springeropen.com 